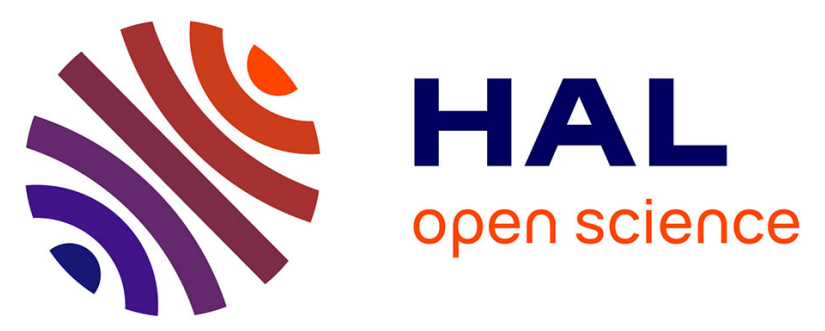

\title{
The macroscopic behavior of pantographic sheets depends mainly on their microstructure: experimental evidence and qualitative analysis of damage in metallic specimens
}

Michele de Angelo, Mario Spagnuolo, Francesco D'annibale, Aron Pfaff, Klaus Hoschke, Aviral Misra, Corinne Dupuy, Patrice Peyre, Justin Dirrenberger, Marek Pawlikowski

\section{- To cite this version:}

Michele de Angelo, Mario Spagnuolo, Francesco D'annibale, Aron Pfaff, Klaus Hoschke, et al.. The macroscopic behavior of pantographic sheets depends mainly on their microstructure: experimental evidence and qualitative analysis of damage in metallic specimens. Continuum Mechanics and Thermodynamics, 2019, pp.Article number 107669. 10.1007/s00161-019-00757-3 . hal-02089078

\author{
HAL Id: hal-02089078 \\ https://hal.science/hal-02089078
}

Submitted on 3 Apr 2019

HAL is a multi-disciplinary open access archive for the deposit and dissemination of scientific research documents, whether they are published or not. The documents may come from teaching and research institutions in France or abroad, or from public or private research centers.
L'archive ouverte pluridisciplinaire HAL, est destinée au dépôt et à la diffusion de documents scientifiques de niveau recherche, publiés ou non, émanant des établissements d'enseignement et de recherche français ou étrangers, des laboratoires publics ou privés. 


\title{
Michele De Angelo • Mario Spagnuolo • Francesco D'Annibale • Aron Pfaff • Klaus Hoschke • Aviral Misra • Corinne Dupuy • Patrice Peyre · Justin Dirrenberger • Marek Pawlikowski \\ The macroscopic behavior of pantographic sheets depends mainly on their microstructure: experimental evidence and qualitative analysis of damage in metallic specimens
}

\begin{abstract}
Recently the exotic properties of pantographic metamaterials have been investigated, and various mathematical models (both discrete and continuous) have been introduced. However, the experimental evidence available up to now concerns only polyamide specimens. In this paper, we use specimens printed using metallic powder. We prove experimentally that the main qualitative and quantitative features of pantographic sheets in planar deformation are independent of the constituting materials, at least when they can be regarded as homogeneous and isotropic at micro-level. Of course, the absolute value of Young's modulus of constituent
\end{abstract}

Communicated by Francesco dell'Isola.

M. De Angelo

Dipartimento di Ingegneria Civile, Edile Architettura e Ambientale (DICEAA), Università degli Studi dell'Aquila, 67100 L'Aquila, Italy

E-mail: michele.deangelo.aq@gmail.com

M. De Angelo

Civil, Environmental and Architectural Engineering Department, University of Kansas, Lawrence, KS 66045, USA

M. Spagnuolo $(\varangle)$

CNRS, LSPM UPR3407, Université Paris 13, Sorbonne Paris Cité, 93430 Villetaneuse, France

E-mail: mario.spagnuolo@1spm.cnrs.fr

M. Spagnuolo · F. D’Annibale

International Research Center M\&MoCS, Università degli Studi dell'Aquila, Via Giovanni Gronchi 18 - Zona industriale di Pile, 67100 L'Aquila, Italy

F. D'Annibale

E-mail: francesco.dannibale@univaq.it

A. Pfaff $\cdot$ K. Hoschke

Fraunhofer Institute for High-Speed Dynamics, Ernst-Mach-Institut, EMI, Ernst-Zermelo-Str. 4, 79104 Freiburg, Germany

A. Pfaff

E-mail: aron.pfaff@emi.fraunhofer.de

K. Hoschke

E-mail: Klaus.Hoschke@emi.fraunhofer.de

A. Misra

Blue Valley High School, 6001 159th St, Stilwell, KS, USA

E-mail: aviralmisra15@gmail.com 
material affects the overall reaction force needed to the hard device to impose a given displacement: A first investigation on this effect is also attempted.

Keywords Pantographic structures · Additive manufacturing · Tomography · Generalized continua

\section{Introduction}

In this work, we investigate the mechanical properties of metal-printed specimens of a promising microstructured material, referred to as pantographic metamaterial. It is remarkable that this substructure results in a material with an exotic macroscopic behavior which can be subjected to large deformation while remaining in an elastic regime [1-4]. Notably, the design of the microstructure has been conceived so that its deformation energy depends on the second gradient of the displacement [5-12]. Morphologically, the substructure can be described as a double array of mutually orthogonal beams, also called fibers, interconnected by elastic cylinders at intersection points, also called pivots $[13,14]$. This survey, specifically, focuses upon reporting and analyzing the results gathered from extensional tests performed on two different samples of specimens with pantographic substructure which consist of (1) three aluminum-printed specimens and (2) four steel-printed specimens, respectively. The experiments establish the fulfillment of the so-called BIAS extension test for all the specimens. (This test is specifically called BIAS extension and not only extension, because it is performed along a biased direction respect to the fiber direction.) In addition, some of the tests include several loadunload cycles with increasing amplitude as well as compression loading. It is notable that the experimental evidence for pantographic sheets gathered up to now concerns only specimens printed in polyamide, and it was immediately evident that it is necessary to extend the available collection of data to specimens constituted of different materials.

Earlier investigations had given the motivation to a series of papers (see, e.g., [13,15-17]) in which the problem of determining the main exotic properties of pantographic metamaterials has been carefully investigated. Various mathematical models have also been proposed, with the aim of finding a reasonable compromise between predictive capacity and computational feasibility. The models introduced up to now can be classified into two types (1) discrete, as in [13,16,18-21], wherein a finite set of rotational and extensional springs are introduced to describe the complex deformation phenomenon occurring in the microstructure, and (2) continuous, as in [13,19,22-24], which can be further distinguished into purely continuous ones, wherein generalized plate models are used (of the same kind of those proposed, e.g., in [25-29]) and into hybrid discrete/continuous ones, wherein beams (i.e., 1D continua) form lattices by means of interconnecting pivots placed at finite distances (see [30-35]).

The relationship between discrete and continuous models can be established via homogenization methods as mentioned in [5,7,13,30,36-41]. Also, interesting results have been found in statistical mechanics which prove how, using precise mathematical argument, fluid continua can be derived from discrete microscopic system via homogenization methods (see, e.g., the reviews $[42,43]$ ). However, we remark that the standard procedures used in $[44,45]$ cannot be used when three point interactions at micro-level are not negligible or when relevant bending energy arises in beam lattices. In spite of the relevant and rigorous results obtained in homogenizing microscopically inhomogeneous systems (also when thermal phenomena are involved), for systems which are fluids macroscopically as shown, e.g., in [46-49], as well as for different classes of biological systems,

C. Dupuy $\cdot$ P. Peyre · J. Dirrenberger

Laboratoire PIMM, Arts et Métiers-ParisTech, CNRS, Cnam, 151 bd de l'Hôpital, 75013 Paris, France

C. Dupuy

E-mail: corinne.dupuy@ensam.eu

P. Peyre

E-mail: patrice.peyre@ensam.eu

J. Dirrenberger

E-mail: justin.dirrenberger@ensam.eu

M. Pawlikowski

Institute of Mechanics and Printing, Warsaw University of Technology, Warsaw, Poland

E-mail: m.pawlikowski@wip.pw.edu.pl 
see, e.g., [50,51]), the problem of homogenizing macroscopically solid behavior remains open if rigorous reasonings of statistical mechanics are to be employed. Therefore, heuristic methods, including mixed micromacro- and ad hoc phenomenological approaches, are expected to play a relevant role in the modeling of the structured media which we consider here.

In the research which we describe in this paper, it was possible to use specimens printed using metallic powder. Some of the latest techniques collected under the name of additive manufacturing (AM) have been employed whose challenge was to fabricate the specimens with well-refined pantographic substructure. We are aware of the fact that the obtained micro-material cannot be regarded to have the same micro-mechanical properties as the material obtained by a melting process. The SEM views in Fig. 12 clearly show that at length scales much smaller than the beam cross-sectional size, the material appears to have a porous microstructure; hence, the classical continuum Cauchy model cannot describe its complex deformation phenomena. In view of the above, granular micro-mechanical models should be employed in order to consider the granular nature of the constitutive material [52-59]. Here, we show based upon experimental measurements that the main qualitative mechanical properties of pantographic sheets (considering planar deformation) appear to be independent of the particular constituting materials. Further these mechanical properties can be described mathematically if these materials, at micro-level, can be suitably modeled as being homogeneous and isotropic. In this paper, a first investigation is described to evaluate the elastic range in BIAS extension tests, the resilience to imperfection and micro-damage and nonlinearity, rupture mechanisms and ultimate failure of considered novel metallic specimens. Comparisons are made between specimens fabricated from aluminum and steel, respectively, remarking upon the similarities and differences in their exotic mechanical properties. These observations are further compared with the ones exhibited by polyamide specimens. A preliminary interpretation of the results, considering the existing theoretical model for pantographic structures, is also described.

\section{Additive manufacturing of steel and aluminum specimens}

Recent advancements in the technical capability of production and designing processes permit fabrication of materials having specific microstructures at small length scales, which have the ability to strongly condition the macroscopic mechanical behavior of the material. The fabrication of the pantographic structure considered herein, and other complex geometries, can be now realized using " $3 D$ printing," also referred to as additive manufacturing (AM). For example, selective laser sintering (SLS) have been already employed for the production of the lattice structures in $[60,61]$. 3D printing is used to create objects with complex shapes in layer-by-layer manner utilizing some precursor constitutive material. Most 3D printing processes employ wires or powders made up of metallic or polymeric material which assume the designed shape by interacting with an energy source. For fabrication with 3D printing, the object must be designed and its three-dimensional geometry generated using a CAD software. The geometry is then discretized into a triangular/tetrahedral mesh and saved in the form of stl file. Such a file is then used as an input for an AM software where the 3D geometry is sliced into layers, whose thickness can be set according to the needed resolution and machine capabilities, and the object to be built is positioned on the building platform. Before the printing process can start, it is necessary to design the supports which connect the object to the building platform and take on the functions of (1) supporting the part during the printing process, (2) dissipating heat and (3) avoiding thermal distortion. The particular case of metal additive manufacturing requires a specific care to the minimization of overhanging areas where overheating zones usually are located and provoke a deterioration of surface roughness.

The so-called powder bed processes are certainly the most promising among the AM techniques. This category includes the selective laser melting (SLM), also called laser beam melting (LBM), and electron beam melting (EBM). The production process employs a laser (or electron) beam to melt a thin layer of powder. A resolution can be defined for such a process based on the size of the laser beam, being usually in the range between 50 and $100 \mu \mathrm{m}$, and the height of the powder layer, being in the range between 20 and $50 \mu \mathrm{m}$. Generally, the overlapping of hundreds of welding beds (200-300 $\mu \mathrm{m}$ in width) is needed to build a part (about $500 \mathrm{~m}$ of bead $/ \mathrm{cm}^{3}$ ), and the melting process is performed under shielding inert gas in order to prevent the oxidation of the powder. The shapes which can be built are complex and the objects, typically, have a satisfactory mechanical behavior. 


\subsection{Manufacturing of steel pantographic structures}

In this survey, the SLM125HL setup from SLM solutions has been used to create the pantographic structure. This machine is equipped with a $400 \mathrm{~W}$ YAG laser (YLR-400-WC) at a wavelength of $1070 \mathrm{~nm}$. Scanning speed varies from 400 to $1500 \mathrm{~mm} / \mathrm{s}$, while the thickness of the powder layer is in the range between 30 and $100 \mu \mathrm{m}$. The minimum diameter of the laser at the focus point is about $70 \mu \mathrm{m}$. The powder employed is the $316 \mathrm{~L}$ stainless steel having spherical particles whose least diameter size is $37 \mu \mathrm{m}$ (CILAS 920). As mentioned above, the manufacturing of the part is preceded by the proper positioning of the $3 \mathrm{D}$ geometry in the printing volume using the MAGICS - Materialise software. As depicted in Fig. 1, the specimens were positioned orthogonally to the building platform even though a tilt angle of $45^{\circ}$ would have been preferable for the realization of the pivots. Despite the significant technological achievements represented by such manufacturing technologies, one has to consider that the objects obtained are very sensitive to the location and the number of supports whose inadequate positioning could result in widespread microstructural flaws. Furthermore, the rough surfaces in Fig. 2a, b indicate the possibility of appreciable porosity which, however, potentially can be suppressed by heat treatments such as hot isostatic pressing (HIP), resulting in almost fully dense metallic alloys. (Such postprocessing was not performed on the samples presented in the next sections.)

\subsection{Manufacturing of aluminum pantographic structures}

The following investigations were conducted with a commercial LBM system (EOS M 400), equipped with a $1 \mathrm{~kW}$ laser unit (YLR series, CW laser, wavelength $1070 \mathrm{~nm}$ ). All objects were manufactured of AlSi10Mg

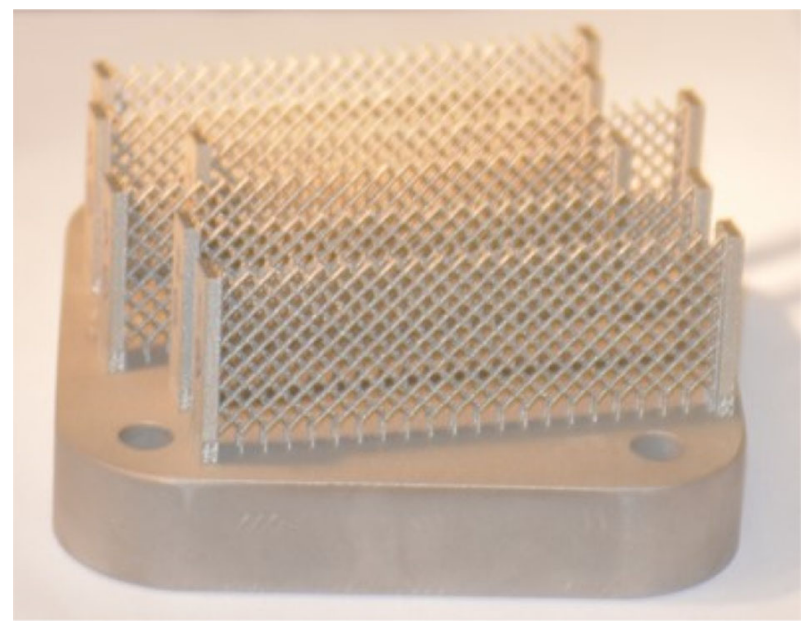

Fig. 1 Manufactured steel samples

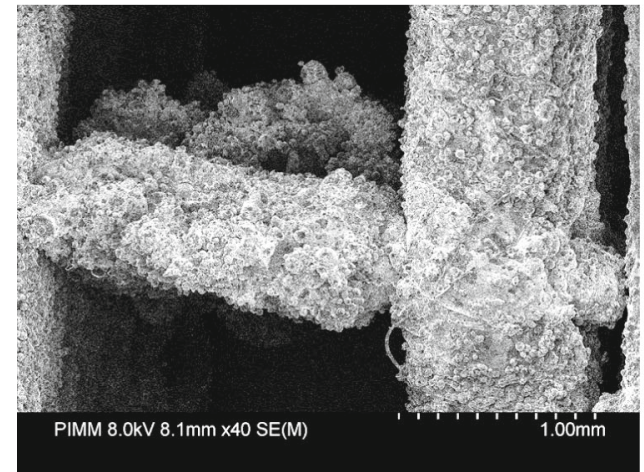

(a) connection at the middle of the sample.

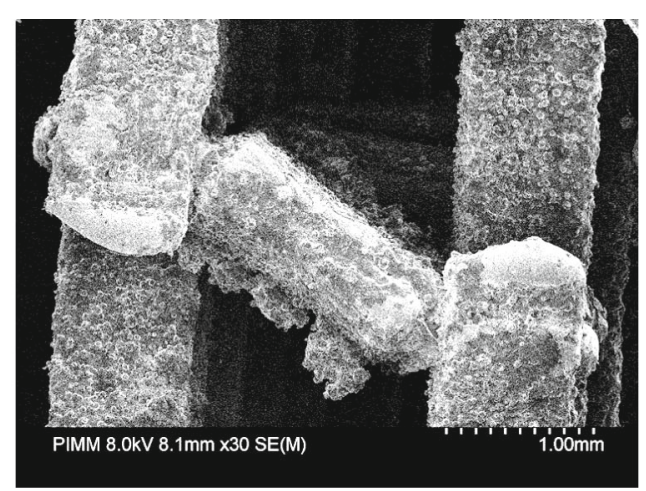

(b) connection at the external point of the sample.

Fig. 2 SEM view of the beam pivot connection after tensile testing 


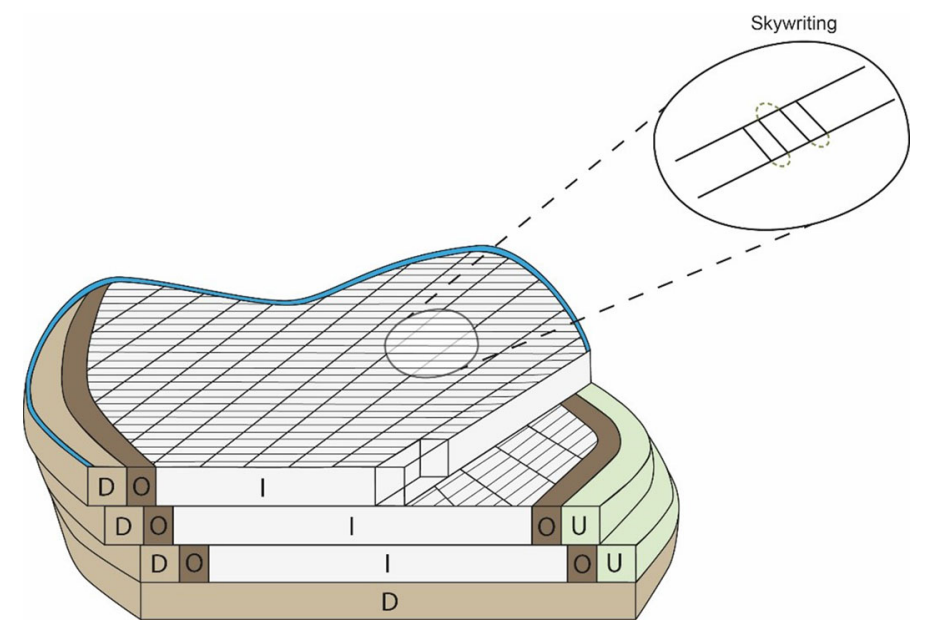

Fig. 3 Example of a basic exposure strategy (stripe strategy) and exposure areas. D: Downskin; U: Upskin; I: Inskin; O: Overlap; Blue: Contour exposure (color figure online)
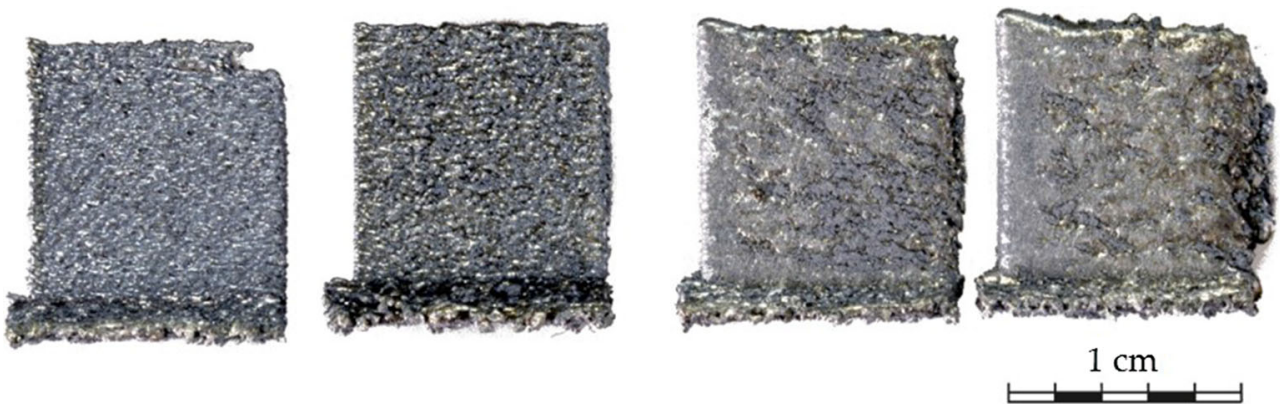

Fig. 4 Lamellas manufactured by a single laser track per layer, showing the impact of inertia (left sides) and interrupt delay (right side). Left to right: increasing energy density

(PSD: D10: $12.28 \mu \mathrm{m}$; D90: $43.22 \mu \mathrm{m}$ ) processed in $90 \mu \mathrm{m}$ layers under the influence of a heated building platform $\left(165^{\circ} \mathrm{C}\right)$. A shield gas flow was applied parallel to the top layer of the powder bed to remove any side products arising from the welding process.

General exposure strategy The process control and resulting material characteristics are intricate due to the incremental creation of material. An exposure strategy (arrangement of laser tracks) is necessary to create a volume using a spot-like energy source like a laser beam. The exposure strategy in combination with exposure parameters like laser power and exposure speed defines the material microstructure and therefore its characteristics. Due to different thermal boundary conditions, a part is usually divided into areas of different parameter settings (see Fig. 3). Areas in a surrounding of low thermal conductivity (e.g., powder) require different parameter settings compared to areas with increased thermal conductivity (e.g., surrounding solid material) in order to create a material of high quality (regarding factors like porosity, homogeneity or microstructure).

Laser track characteristics Usual exposure speeds for the processing of AlSi10Mg can reach $2000 \mathrm{~mm} / \mathrm{s}$. The switch on/off time of the laser unit can take up to $50 \mu \mathrm{s}$. Therefore, the full laser power is reached after a distance of $\sim 0.1 \mathrm{~mm}$. This distance can also be impacted by delays in the electronics controls. This effect can cause different ending points for the laser track (see interrupt delays in Fig. 4). A second effect can be caused by the physical inertia of the projectors mirror, which is resulting in a lower exposure speed in the beginning of the track and therefore in a higher energy input.

Part orientation A proper orientation of a part within the building volume is essential to its quality and errorfree producibility. Acute angles between the building substrate and the part's surface require a support structure. This is due to the residual stress within the material resulting from the rapid cooling rates [62]. Without any 

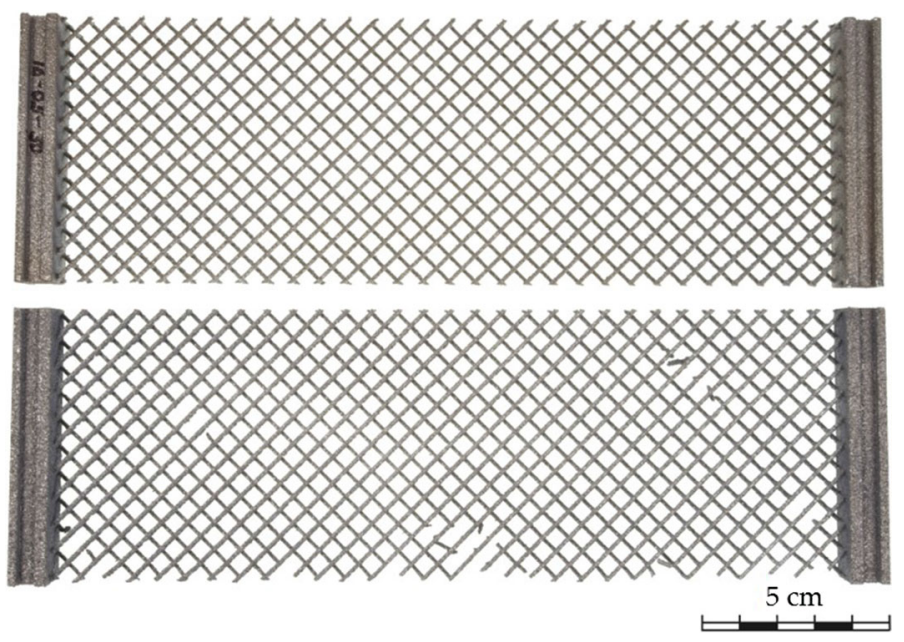

Fig. 5 Pantographic sheet with a beam diameter of $1 \mathrm{~mm}$ manufactured of AlSi10Mg. Bottom: Sample manufactured by standard manufacturing parameters. Top: Sample manufactured by adapted exposure parameters and strategy

connection of the part to the substrate, the part would deform within the process causing the coating unit to jam. Furthermore, surfaces with an acute angle result in a poor surface quality regarding roughness, surface cracks and surface porosity. Therefore, it is advisable to avoid part orientations with major surfaces of an acute angle.

Adapted manufacturing parameters for a metamaterial The pantographic sheet was manufactured in a $45^{\circ}$ angle rotated around its axial line in order to prevent any acute angles. All surfaces show therefore a $45^{\circ}$ angle toward the substrate plate. A further advantage of this orientation is that the exposure cross section within a layer offers more surface than the actual beam cross section and therefore enables longer laser tracks. As a second measurement, a setup of a single exposure area was applied within the lattice. In order to increase the laser track length to a maximum, circular laser tracks were applied instead of a stripe strategy. Furthermore, the exposure speed was minimized, which also required an adaption of laser power and hatch distance (spacing between laser tracks). As a result, it is possible to manufacture the pantographic sheet without any visual damage. A comparison of standard parameters and the adapted manufacturing parameters is illustrated in Fig. 5. The specimens were manufactured under the same building orientation.

\section{Tomographic analyses on aluminum samples}

\subsection{Micro-X-ray CT imaging}

A ZEISS micro-X-ray CT machine was used to acquire the images (ZEISS Xradia 410 Versa 2018). This machine uses X-rays to map the microstructure of an object at micrometer to millimeter scales. The imaging modality works on the principle of density contrast. That is, the X-rays would transmit through the sample such that the areas where less X-rays get through are the denser parts and the areas where more $\mathrm{X}$-rays get through indicate less dense parts in the materials. The $10 \times$ objective was used to image the samples which results in a digital image with a square field of view of side $\sim 1.5 \times 103 \mu \mathrm{m}$ and pixel size $\sim 0.86 \mu \mathrm{m} /$ pixels. A total of 1441 images at the frequency of 4 images per degree of rotation were acquired for tomographic reconstruction. The overall imaging time varied from 8 to $12 \mathrm{~h}$ depending on the exposure time per image. Subsequently, using the Reconstructor software, the images acquired were assembled as a 3D structure shown in Fig. 6. The reconstructed 3D structure has a voxel size of $1.72 \times 1.72 \times 1.72 \mu \mathrm{m}^{3}$. A visual inspection of the reconstructed structure reveals a smooth internal texture for the aluminum with spherical pores of varying sizes. This observation is not unexpected since the SLM process was used for its fabrication. 

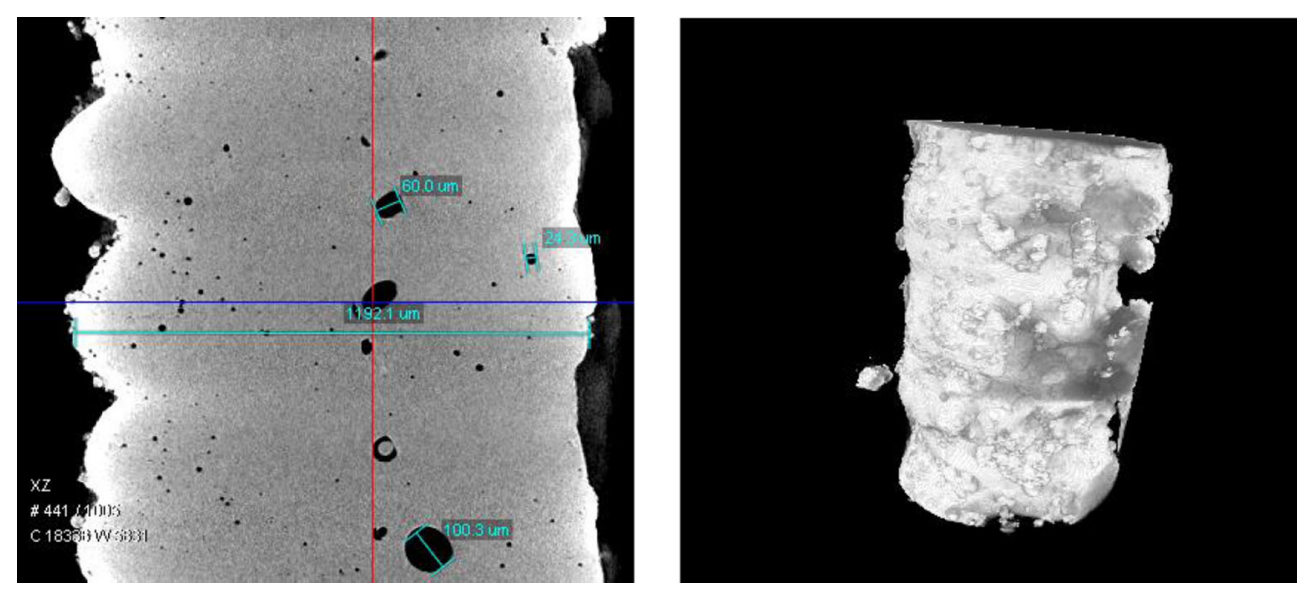

Fig. 6 Reconstructed $10 \times$ Aluminum
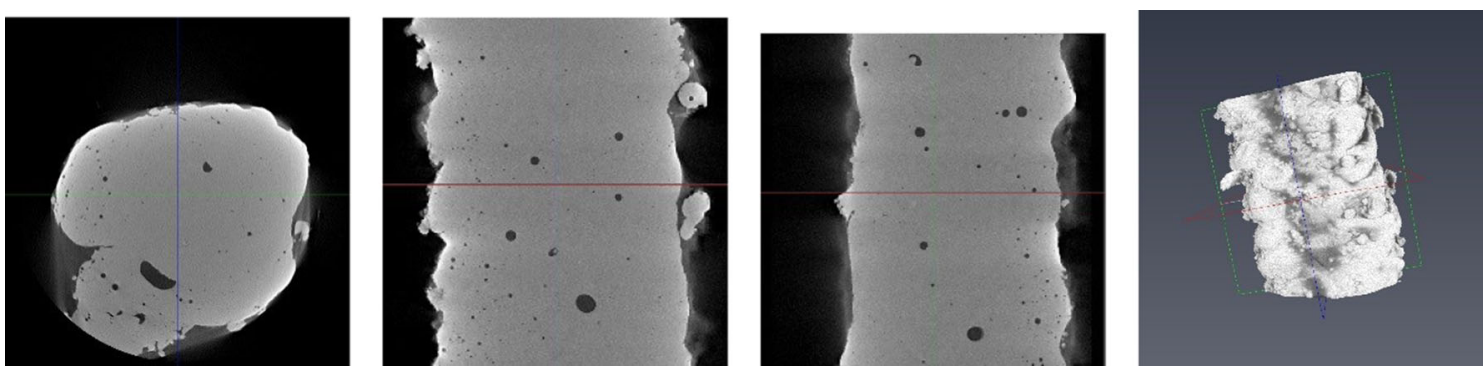

Fig. 7 Selected sections in $x y$-, $x z-, y z$-planes and the 3D solid, of the original reconstructed $\mu \mathrm{XCT}$ image for aluminum specimen, showing irregular boundaries

\subsection{Avizo 3D analysis}

Porosity analysis was performed using the wizard and image segmentation tool of Avizo (Avizo 9.5.0 software). To ensure that the segmentation tool could identify the interior pore spaces, the reconstructions were cropped down to cubes to avoid the irregular boundary effects. Figure 7 illustrates the boundary irregularity in the original reconstruction for aluminum specimen, shown as selected sections in $x y-, x z_{-}, y z$-planes and the 3D solid, respectively. Multiple cubical samples were taken from different locations of the original reconstruction to ensure that the major topographic features (i.e., pore spaces) of the original reconstruction were represented. Figures 8 and 9 give three instances of the cubical samples for aluminum specimen of size $400 \times 400 \times 400$ voxels shown as selected sections in $x y-, x z^{-}, y z$-planes and the 3D solid, respectively. The cubical sample sizes were predicated by the original cross-sectional dimensions of the beam specimens and their orientation in the $x y$-plane. Avizo's segmentation tool was used to define the labels of the material volume versus the pore volume in the cropped cubical samples. Once the areas were defined, Avizo's label analysis tool was used to calculate the image statistics. The porosity analysis wizard was also used to obtain the pore size distribution. Porosity is defined as the ratio of the pore volume to the total volume. The average porosity of the aluminum specimen was found to be $6.54 \%$. For aluminum specimen, the maximum pore size varied from 167.7 to $194.8 \mu \mathrm{m}$, while the median pore size ranged from 4.8 to $7.7 \mu \mathrm{m}$ for the three cubical samples. Figures 8 and 9 show that the pores in these specimens are mostly spherical.

\section{Aluminum-printed structures}

Extensional tests were performed on three aluminum-printed specimens of pantographic structure. The microstructure of the aluminum samples is described by the parameters shown in Fig. 10 whose values are reported in Table 1 . The force versus displacement graphs are obtained by testing the specimens in a so-called BIAS extension test which can be experimentally performed by clamping one of the two sides of the sheet and imposing a longitudinal displacement to the other side. Herein we analyze the behavior under extension 

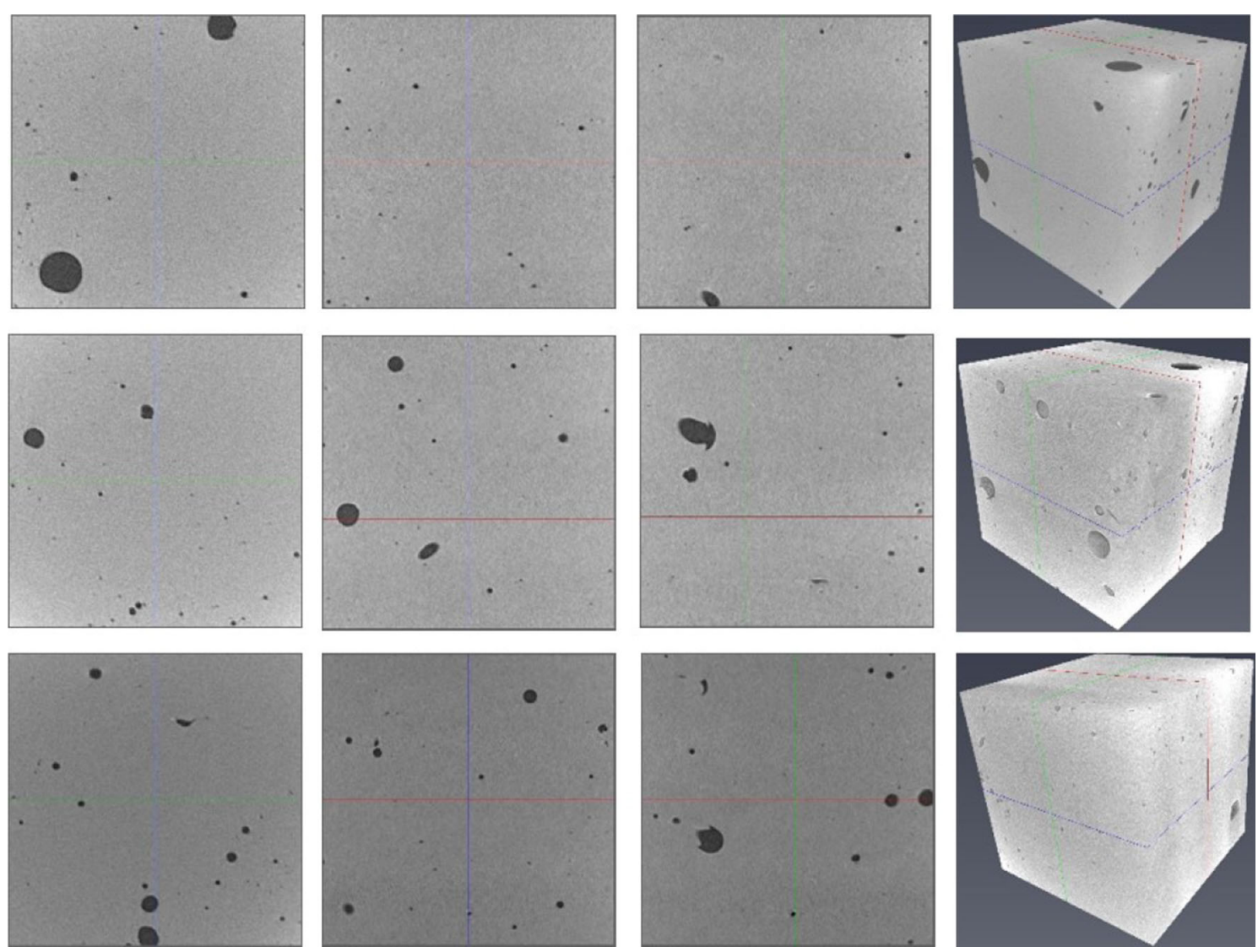

Fig. 8 The columns give selected sections in $x y$-, $x z-, y z$-planes and the 3D solid, respectively, for three cubical samples (rows) cropped from the top, mid- and lower regions of the original reconstructed $\mu \mathrm{XCT}$ image for aluminum specimen
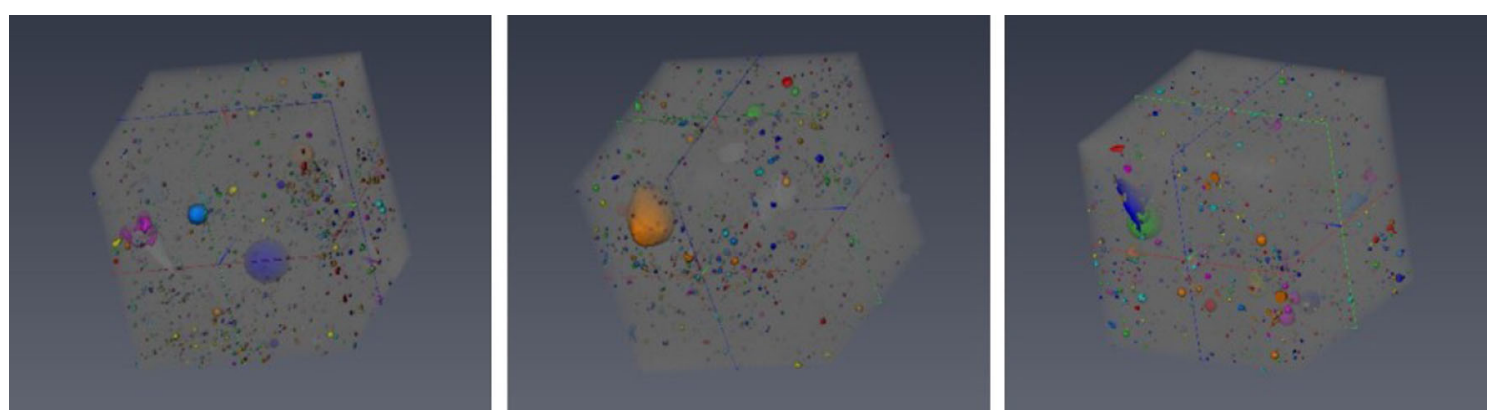

Fig. 9 Pore structures with the three cubical samples cropped from the top, mid- and lower regions of the original reconstructed $\mu \mathrm{XCT}$ image for aluminum specimen. The mostly spherical shapes of the pore spaces can be readily seen

of the three samples in order to determine (1) their elastic range, (2) the incipient plasticity and (3) the ensuing the damage and failure process. According to the prescribed experimental test conditions, three types of bias tests were performed as summarized in Table 2. The first type of test was designed to evaluate the elastic range of considered specimens. For this aim, cyclical extension tests were performed with loading and unloading phases, on specimen designated as sample A. The complete loading history of the test is depicted by the plot in Fig. 11, but we will show each stage of the experiment separately. In Fig. 12a, b are shown the forcedisplacement plots corresponding with the first two load cycles performed on sample A. A fist stretch step of $1 \mathrm{~mm}$ is prescribed, and subsequently, a second load step up to $2 \mathrm{~mm}$ is applied. At the end of each step, the unloading phase follows. The deformation rate is $0.1 \mathrm{~mm} / \mathrm{s}$ to ensure that no inertial contribution occurs. The plots in Fig. 12 clearly show that the trend of both curves is linear, highlighting a direct proportionality between reaction force and imposed displacement. Furthermore, in both graphs the loading and unloading 


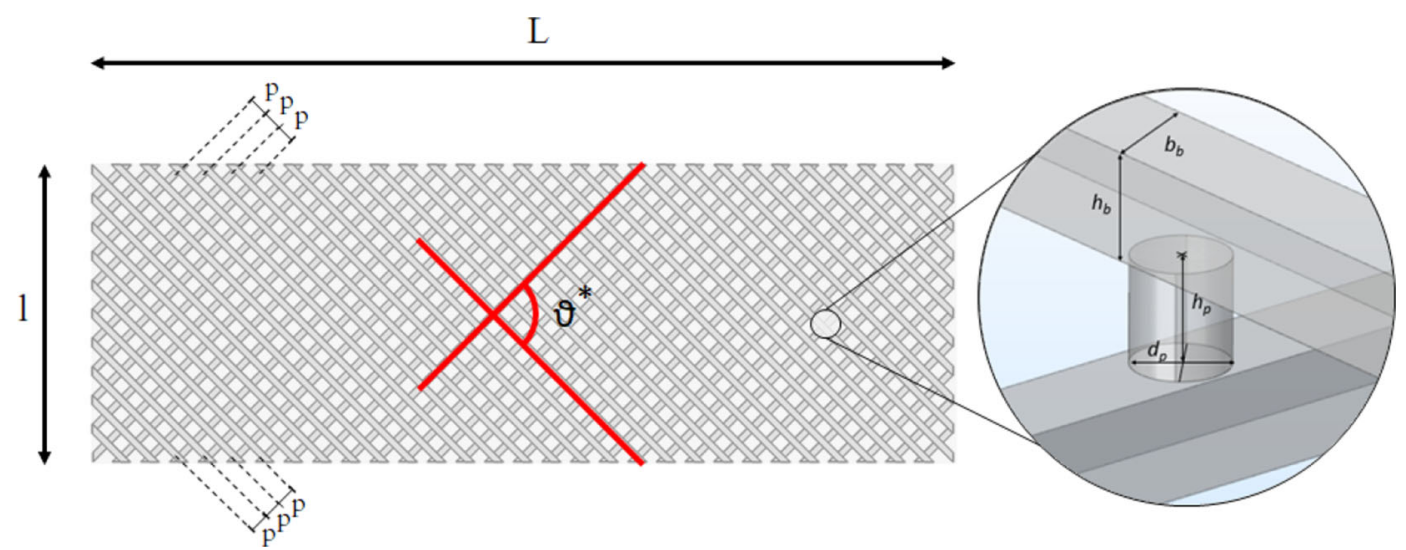

Fig. 10 Geometry and microstructure parameters

Table 1 Fibers and pivot dimensions are measured in millimeter, and angles are measured in radiant

\begin{tabular}{llllllll}
\hline$b_{b}$ & $h_{b}$ & $d_{p}$ & $h_{p}$ & $L$ & $l$ & $\vartheta^{*}$ & $p$ \\
\hline 1.0 & 0.6 & 0.9 & 3.0 & 210 & 70 & $\pi / 2$ & 4.85
\end{tabular}

Table 2 Tests performed on aluminum specimens

\begin{tabular}{lllll}
\hline & Type of test & Cyclic test & Destructive & Deformation rate $(\mathrm{mm} / \mathrm{s})$ \\
\hline Sample A & Extension & Yes & Yes & 0.1 \\
Sample B & extension & No & Yes & 0.33 \\
Sample C & extension & Yes & Yes & 0.05 \\
\hline
\end{tabular}

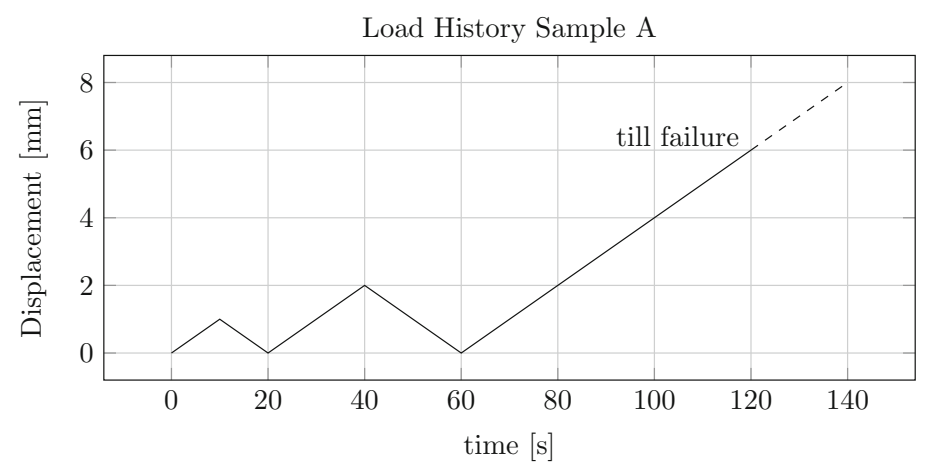

Fig. 11 Displacement versus time plot describing the load history applied to aluminum specimen A

phases almost coincide suggesting a linear elastic behavior. After this cyclic phase, sample A is stretched until complete rupture. As shown in Fig. 13a, a linear stage can be considered up to $3 \mathrm{~mm}$ of elongation, while in Fig. 13b we can notice the initiation of a nonlinear stage. Looking at the whole BIAS extension test on sample A shown in Fig. 14, it can be observed that the mechanical behavior is elasto-plastic with strain hardening until a maximum in the reaction force is reached. This can be really observed by unloading the structure and showing that the deformation has been irreversible (see Fig. 21). After that, a softening part occurs before the first rupture. The first rupture event is related to the collapse of one of the external pivots highlighted in the circle in Fig. 15 that are located at about $\frac{1}{3} L$. In the following, we will give an interpretation of this event on the basis of some specific mechanism similar to the ones studied in [63]. Despite this rupture, the specimen still exhibits a certain load capacity, as at least other three breakages occur before the total failure. In Fig. 16, the failure sequence is shown: Every frame displayed corresponds to a rupture point beyond the first break in the graph. 


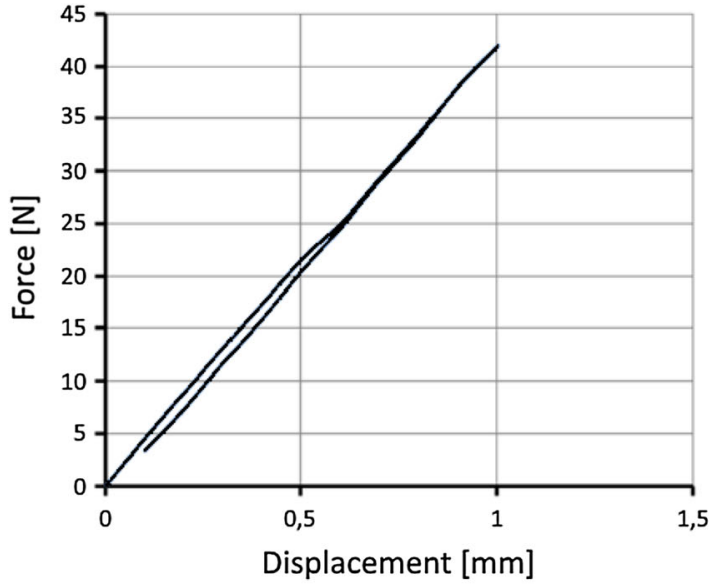

(a) $1 \mathrm{~mm}$ stretch and unloading

Fig. 12 Load-unload cycle on aluminum sample A

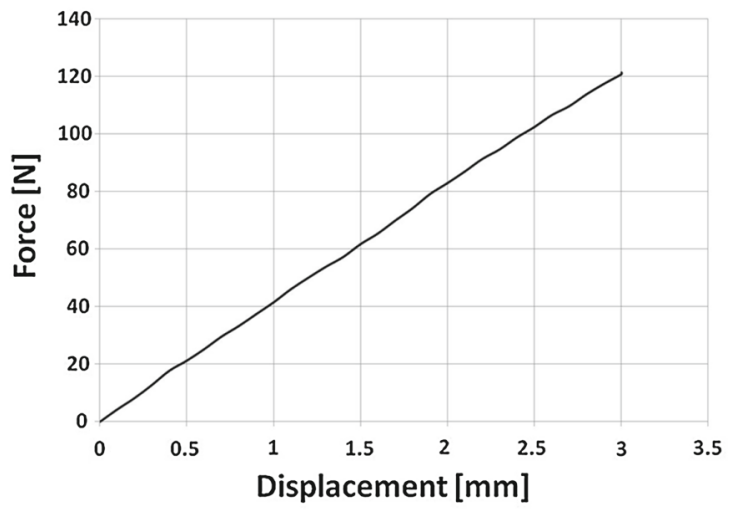

(a) $3 \mathrm{~mm}$ stretch

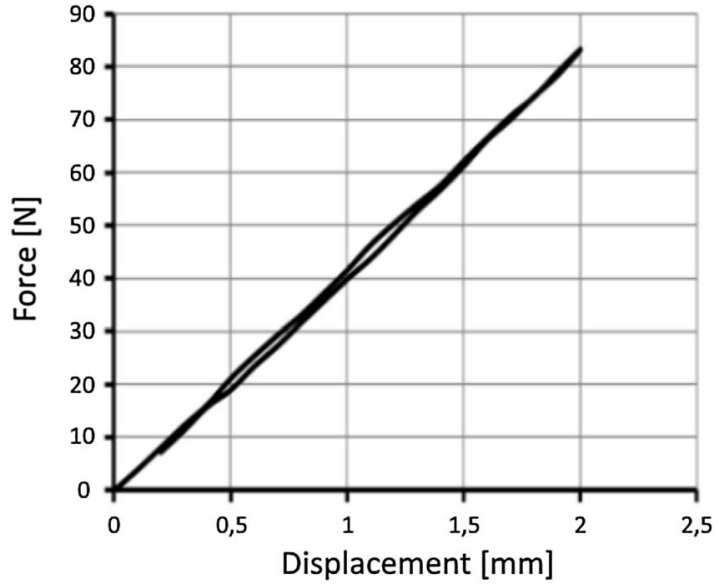

(b) $2 \mathrm{~mm}$ stretch and unloading

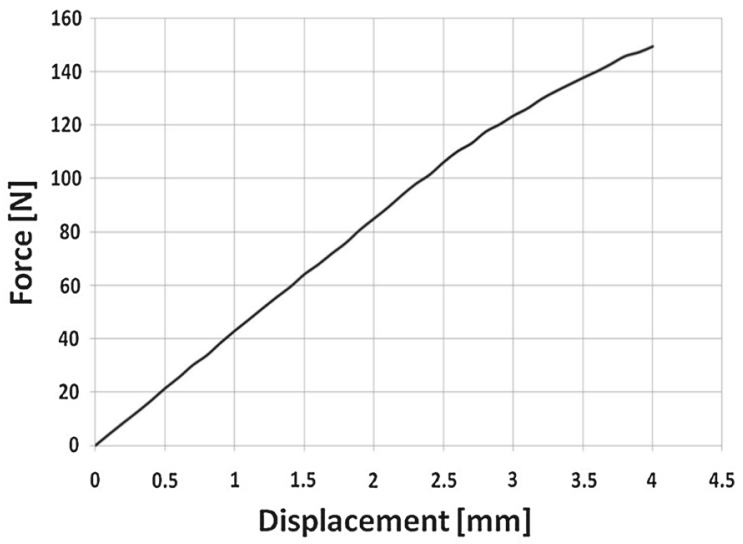

(b) $4 \mathrm{~mm}$ stretch

Fig. 13 Limit of elastic range of aluminum sample A

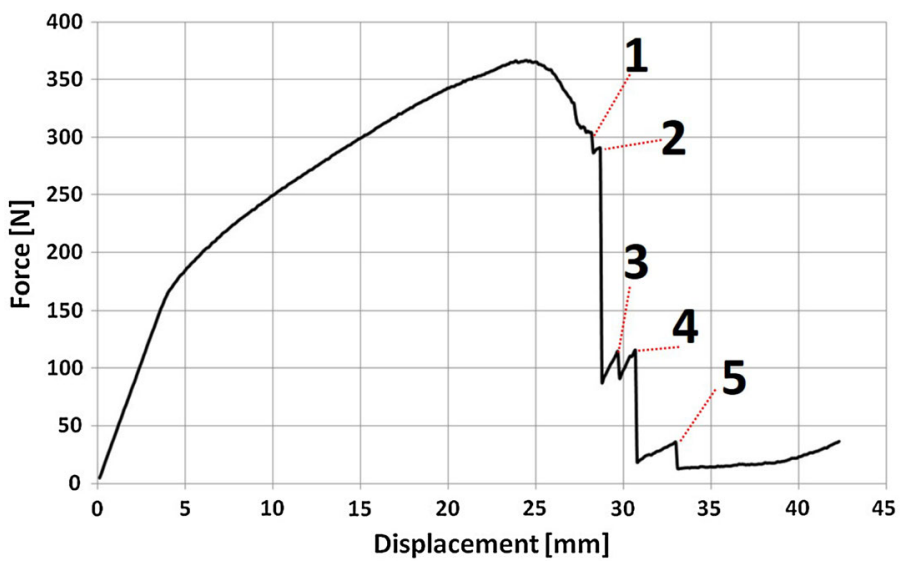

Fig. 14 Entire extensional test graph of aluminum sample A

We next compare the described results (sample A) to the ones relative to the second sample (sample B). Sample B has been stretched until complete rupture without a previous cyclic test, at a deformation rate of $0.33 \mathrm{~mm} / \mathrm{s}$ (see Fig. 17). Although for sample B, the elastic phase has not been determined specifically, it is 


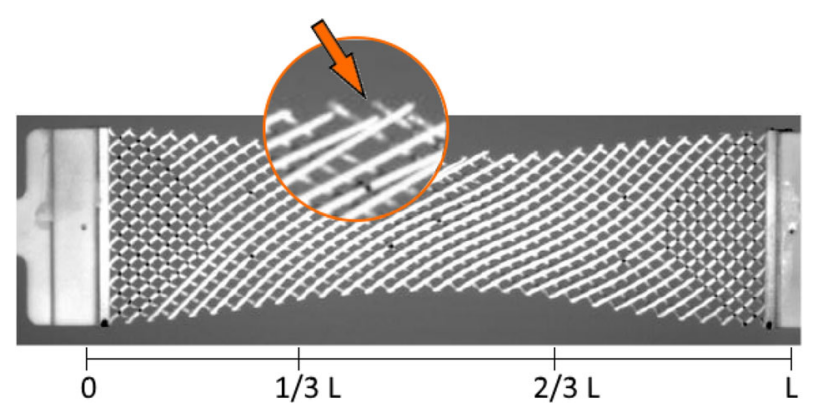

Fig. 15 Aluminum sample A first break

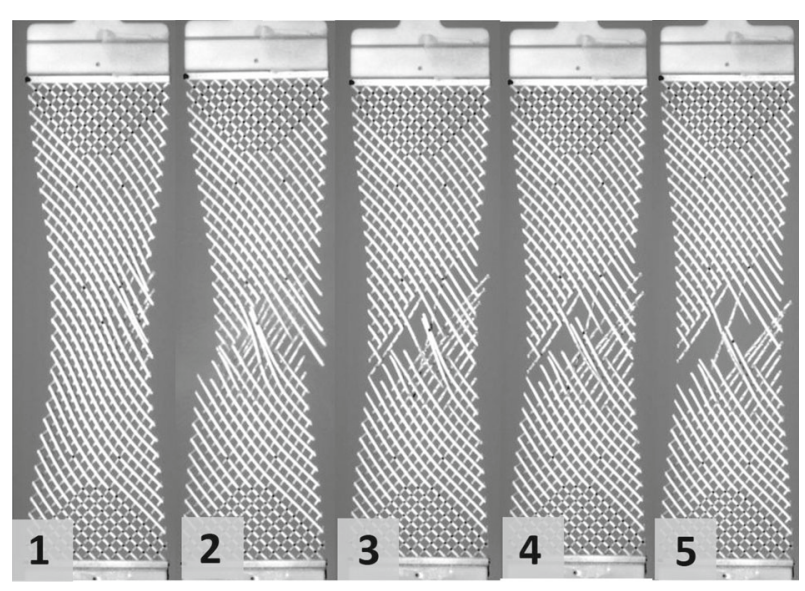

Fig. 16 Aluminum sample A all breakages

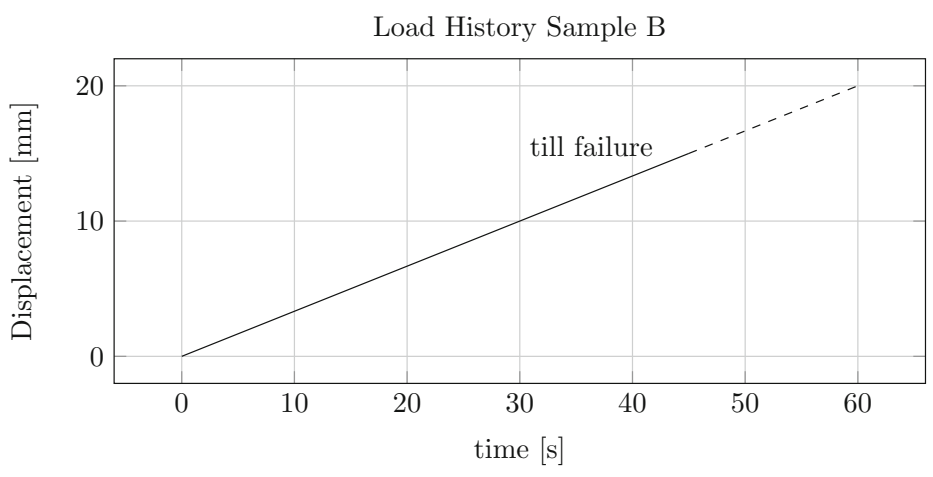

Fig. 17 Displacement versus time plot describing the load history applied to aluminum specimen B

possible to recognize a linear part of the force-displacement curve. The plot shows an overall strain hardening behavior and a softening branch before the first rupture. After the proportionality limit (settled by hypothesisby comparing the plot in Fig. 18 with the result observed for sample A-at $2 \mathrm{~mm}$ of stretch), the trend becomes nonlinear for higher displacement values, exhibiting strain hardening. For sample B, the softening seems to trigger at $8 \mathrm{~mm}$ of elongation and progresses gradually till complete rupture. It is interesting to compare the behavior of samples A and B. It is clear that the shape of the two curves is very similar, and likewise sample B, also sample A has an initial linear part that corresponds to a linear elastic behavior. Despite a very similar overall trend, there are significant differences between the two specimens (Fig. 19). The most obvious is the resistance, in terms of reaction force provided, and the capability to deform. Figure 20 shows that sample B begins to soften much earlier (before $10 \mathrm{~mm}$ of displacement) compared to sample $\mathrm{A}$, which stretched twice as much before the commencement of damage softening. 


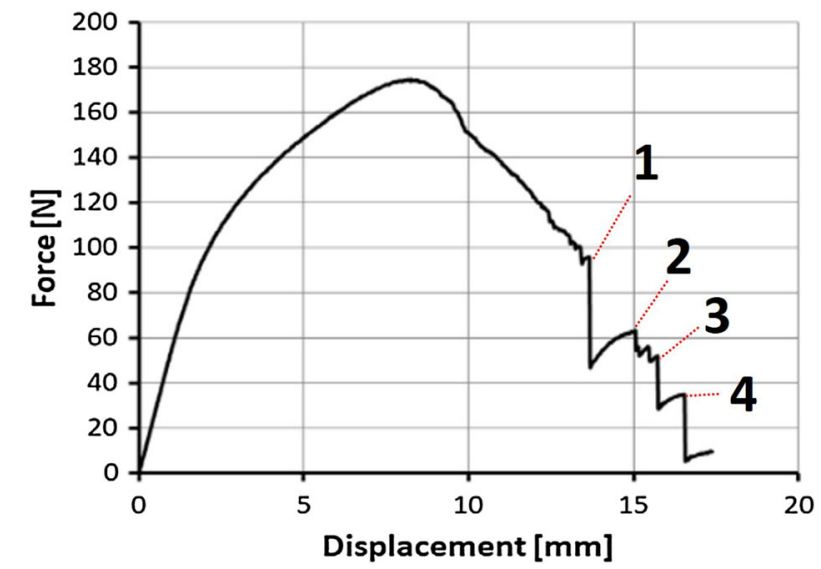

Fig. 18 Entire extensional test graph of aluminum sample B

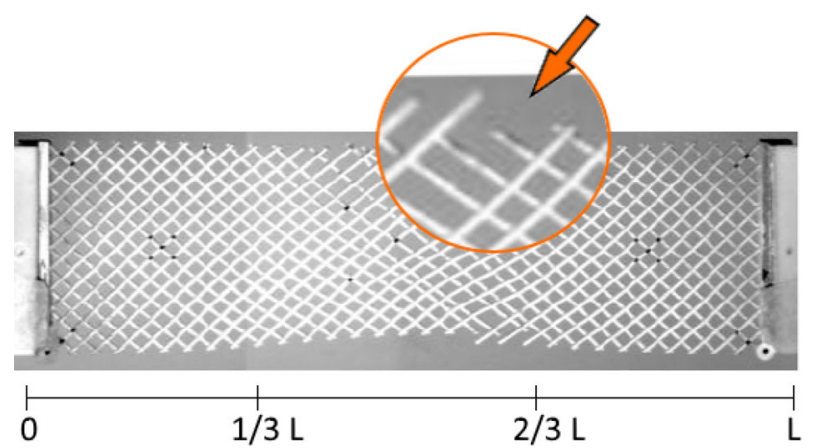

Fig. 19 Aluminum sample B first break

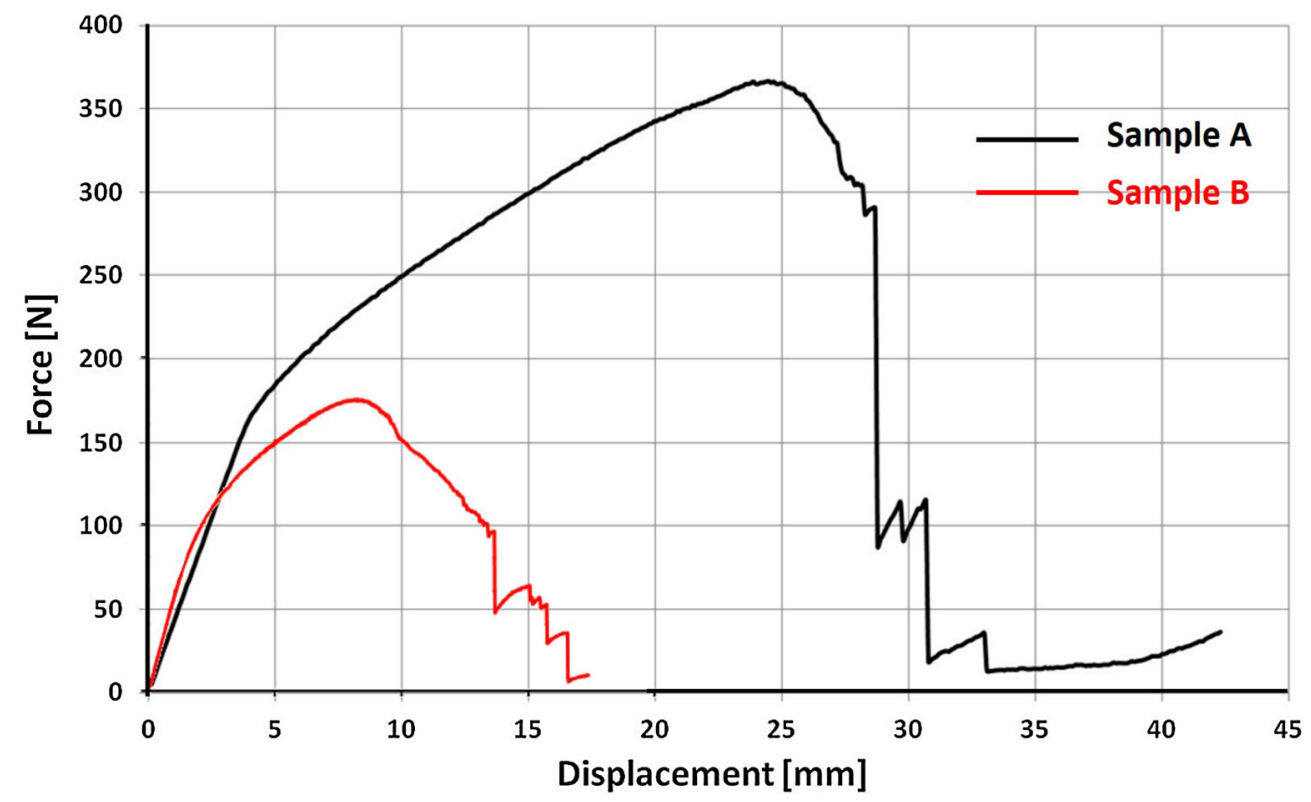

Fig. 20 Comparison between bias test results on sample A and B

We now present the results relative to sample $\mathrm{C}$, subjected to a cyclic extension test. This experiment was designed to examine the behavior beyond the elastic limit of considered specimen. Sample $C$ has been submitted to a higher number of load-unload cycles as given by the graph in Fig. 23. The first two cyclic phases, which 


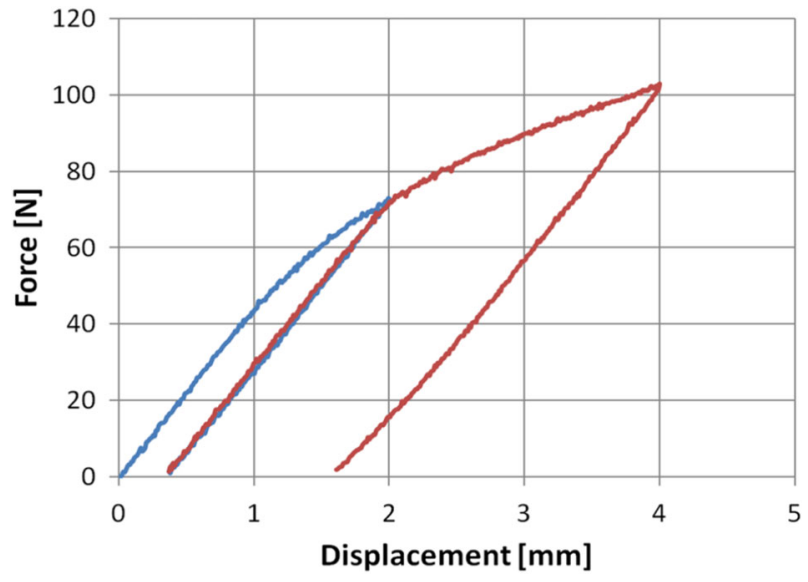

Fig. 21 Two load cycles applied on aluminum sample C

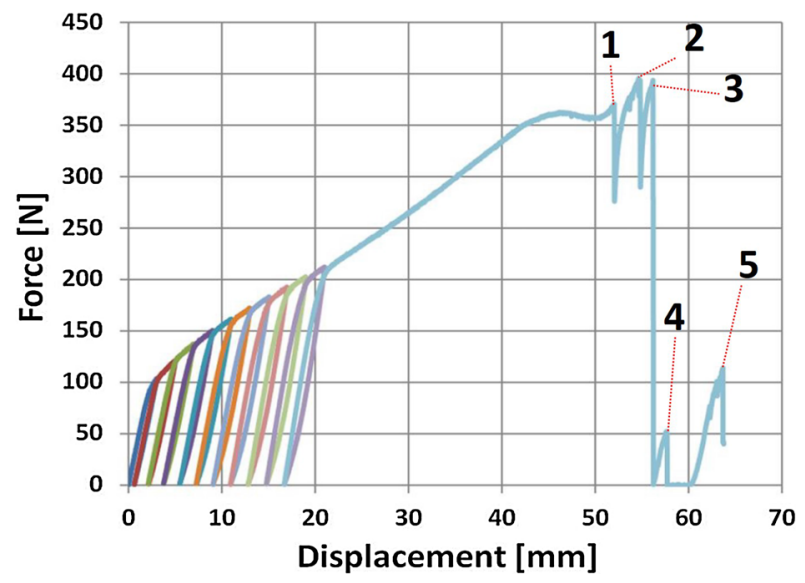

Fig. 22 Cyclic test and stretch until failure of aluminum sample $\mathrm{C}$

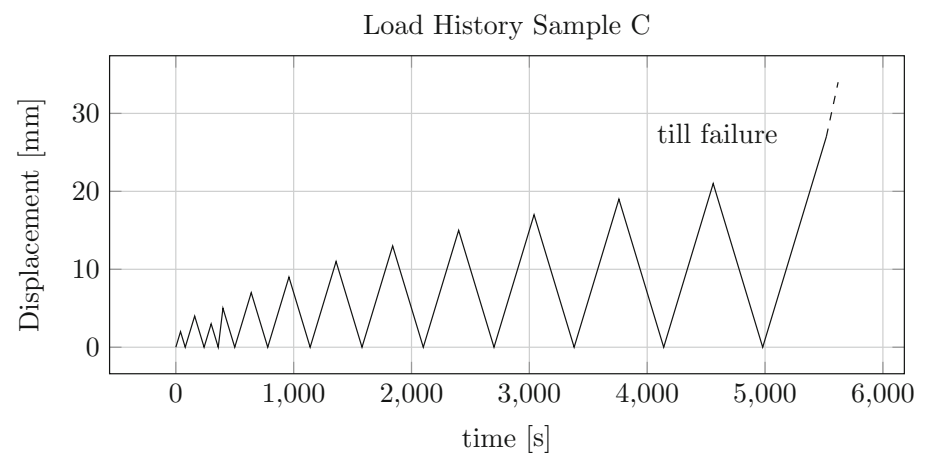

Fig. 23 Displacement versus time plot describing the load history applied to aluminum specimen C

prescribe an elongation up to $2 \mathrm{~mm}$ and unloading and subsequently an elongation up to $4 \mathrm{~mm}$ and unloading, are summarized by the force-displacement plot in Fig. 21. In first stage, the force-displacement relation is linear (see Fig. 21) up to an elongation of about $1 \mathrm{~mm}$; after that, a nonlinear stage starts. The subsequent cycles are carried out beyond proportionality limit under the condition of plasticized material. Indeed, a residual deformation can be evaluated at the end of each unloading stage. We can remark that, when a greater number of load cycles are carried out, the shape of the resulting force-displacement curve appears to have little influence of the loading cycles as every cycle shows the same overall trend (see Fig. 22). At the end of the cyclic part, the loading is continued until total rupture of the specimen. As for the two previous cases, the 


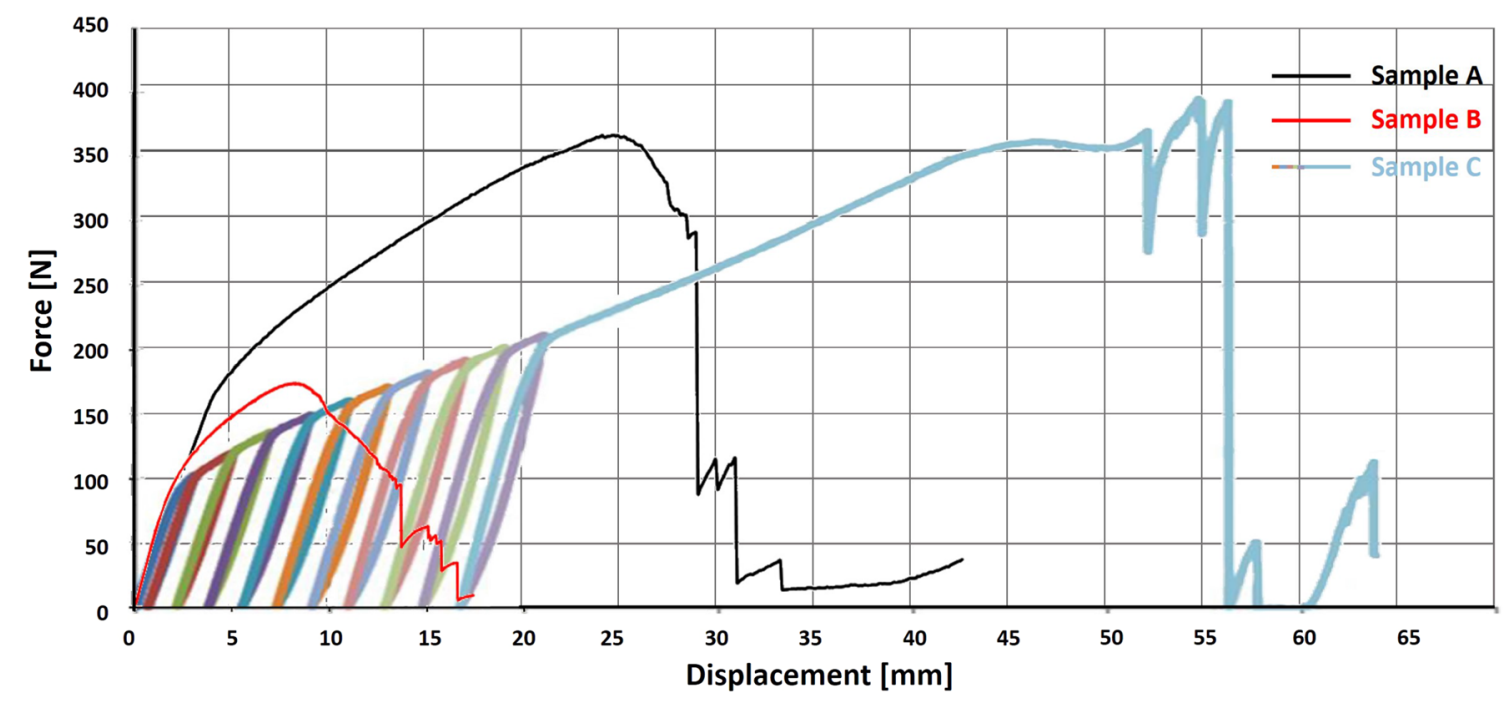

Fig. 24 Comparison between the force-displacement plots relative to samples A, B and C

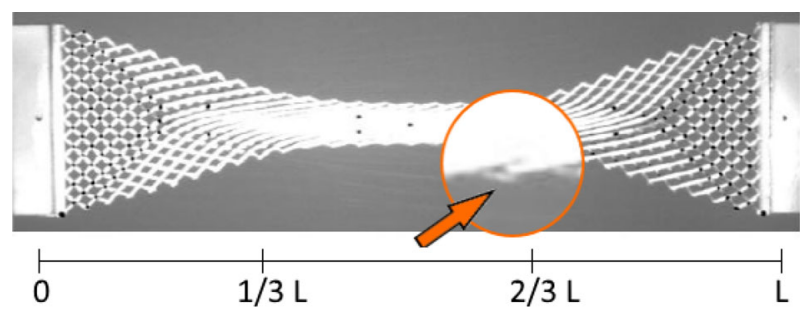

Fig. 25 Aluminum sample C first break

softening represent the beginning of the damage of the specimen and the activation of the rupture mechanism, but the softening phase is much less evident. Indeed, the reaction force does not have a relevant drop and its value even rises again after a small increase in stretch. Also, when the first break occurs the force does not decrease by a significant value. The second and third break happen at force level even higher, reaching $400 \mathrm{~N}$ (Fig. 23).

Comparing these results to the previous cases, some similarities and differences emerge (see Fig. 24). The overall trend is very similar to that shown by samples A and B before the commencement of damage. Moreover, in this case also the specimen starts to rupture due to the collapse of a pivot, whose position is highlighted in Fig. 25. Looking at the comparison plots reported in Fig. 24, the main difference is the greater deformation reached by the specimen $\mathrm{C}$ compared with sample $\mathrm{A}$ and $\mathrm{B}$. It is remarked that the three samples have the same slope for the linear stage but a very different behavior after that, although they have the same microstructure and were fabricated in a single batch.

\section{Inox-printed structures}

We now describe the results obtained for BIAS extension test performed on inox-printed specimens. As in the case of aluminum specimens, the intent is to evaluate the limit of elastic stage, the behavior in the plastic phase and the initiation of the failure process. The setup for the tests is the same as for the aluminum specimen. In addition, the experiments prescribe both cyclic and monotonic tests. The details of the type of the test performed for every sample are listed in Table 3. The microstructure is same as the aluminum-printed specimens, and it is described by the parameters listed in Table 4 (Fig. 26).

We first discuss the results of the tests performed on sample S1. This specimen has been subjected to different loading stages (see Fig. 28) which are (1) a cyclic extension phase, (2) a compression phase and then (3) a stretch phase up to rupture. The complete load history applied on sample S1 is plotted in Fig. 27. 
Table 3 Tests performed on inox-printed specimens

\begin{tabular}{lllll}
\hline & Type of test & Cyclic test & Destructive & Deformation rate $(\mathrm{mm} / \mathrm{s})$ \\
\hline Sample S1 & Extention and compression & Yes & Yes & 0.16 \\
Sample S2 & Extention & No & Yes & 0.5 \\
Sample S3 & Extention & No & Yes & 0.5 \\
Sample S4 & Extention & No & Yes & 0.5 \\
\hline
\end{tabular}

Table 4 Fibers and pivot dimensions are measured in millimeter, and angles are measured in radiant

\begin{tabular}{llllllll}
\hline$b_{b}$ & $h_{b}$ & $d_{p}$ & $h_{p}$ & $L$ & $l$ & $\vartheta^{*}$ & $p$ \\
\hline 0.8 & 1.0 & 0.4 & 0.8 & 90 & 30 & $\pi / 2$ & 1.48 \\
\hline
\end{tabular}

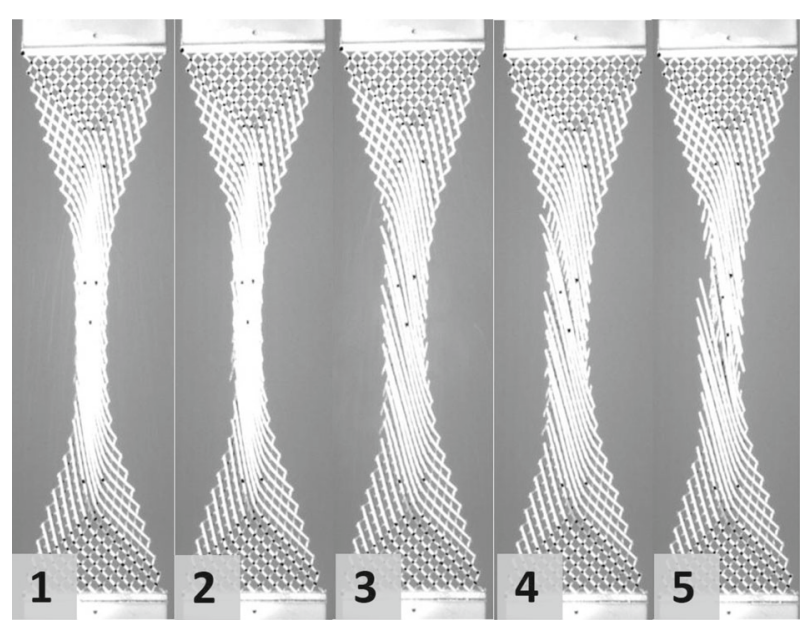

Fig. 26 Aluminum sample $\mathrm{C}$ all breakages

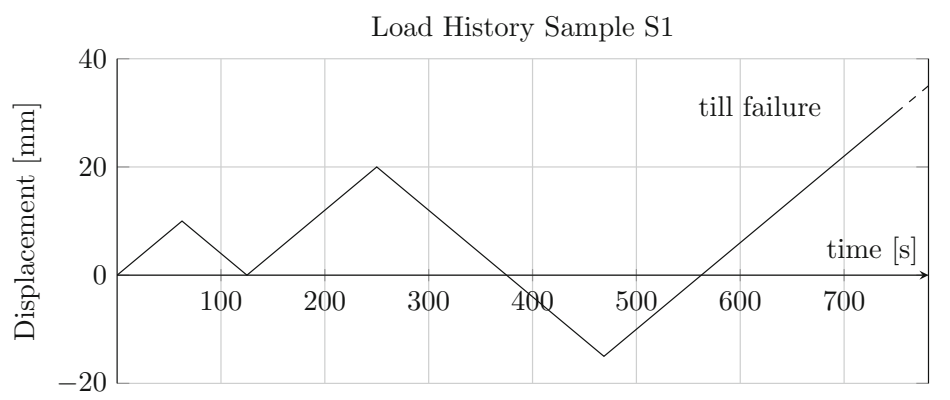

Fig. 27 Displacement versus time plot describing the load history applied to steel specimen S1

In Fig. 28, the top graph shows the first cyclic stage, for the two extension cycles of $10 \mathrm{~mm}$ each. In this stage, the linear elastic behavior cannot be clearly demarcated. Indeed, the curve appears to exhibit nonlinear behavior immediately upon loading. Further, at the first unloading corresponding to $10 \mathrm{~mm}$ stretch, a residual elongation is measured upon unloading suggesting the onset of plastic behavior. Referring again to the top graph in Fig. 28, the second cycle seems to underline an isotropic strain hardening given the way the curve resumes its path upon reloading. A second stage involving a compression test on sample S1 is depicted in the middle graph in Fig. 28. Also in this case, there is no linear branch. It appears that the shape of the compression curve has some similarities to the first cycle of tension test reported in the top graph in Fig. 28. Notably, the values of the reaction force are approximately the same but with opposite sign. The bottom graph in Fig. 28 presents the force versus displacement plot up to rupture for the sample S1 under tension. The maximum axial force is about $2500 \mathrm{~N}$ at $30 \mathrm{~mm}$ of stretch. Overall, the graph shows a work hardening of the specimen, 


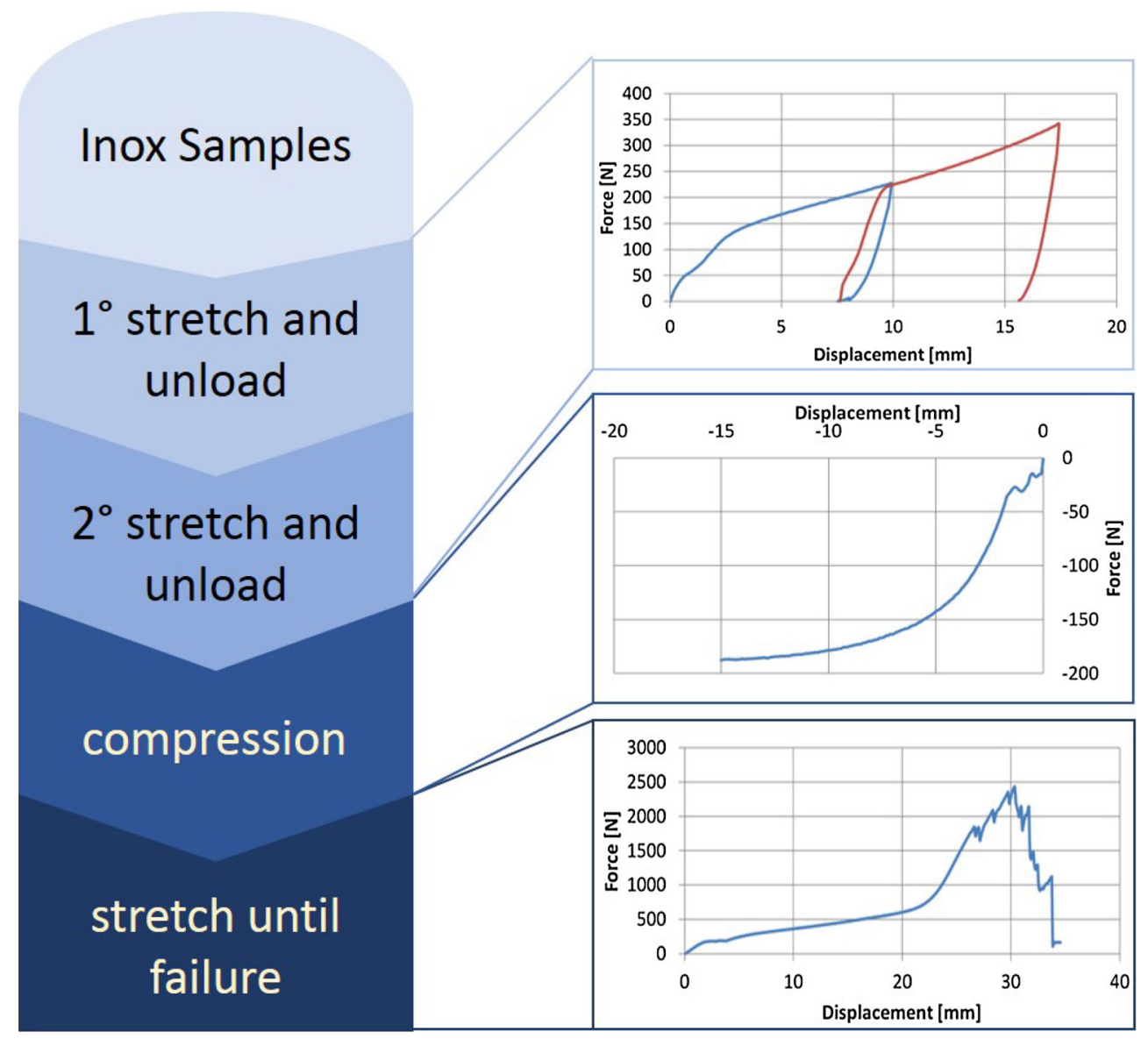

Fig. 28 Summary scheme of all experiments performed on inox sample S1

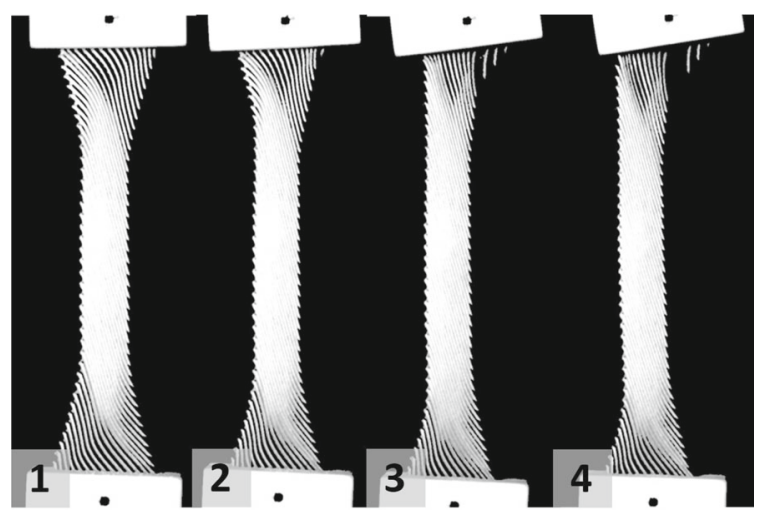

Fig. 29 Propagation of the failure under BIAS extension test performed on inox sample S1

which is much clearer after $22 \mathrm{~mm}$ of stretch. Indeed, the rupture phase is preceded by a last step in which the reaction grows very rapidly. Some fluctuations are recorded before the first rupture point, but their trend is still upward, highlighting a typical behavior of pantographic structures. (We will remark resiliency as a feature typical of pantographic structures.) Furthermore, when the first rupture occurs, the sample still has capacity of deformation before the definitive failure. The rupture behavior registered for sample S1 shows a fundamental difference with respect to aluminum samples: In this case, the failure is caused by tensile collapse of the outer fiber on one of the two constrained sides, as shown in Fig. 29. 


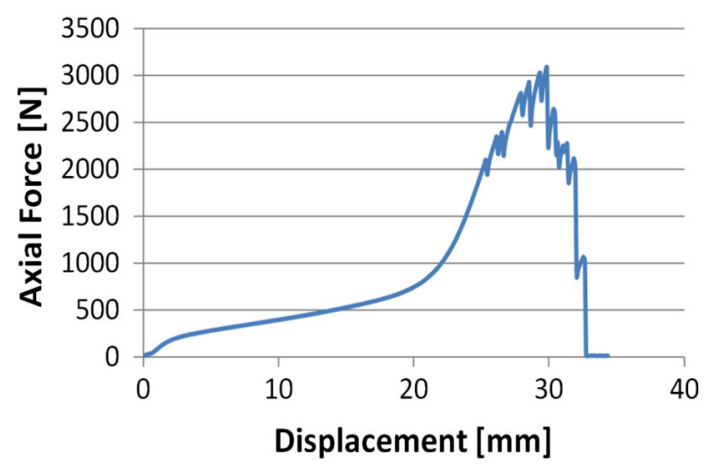

(a)

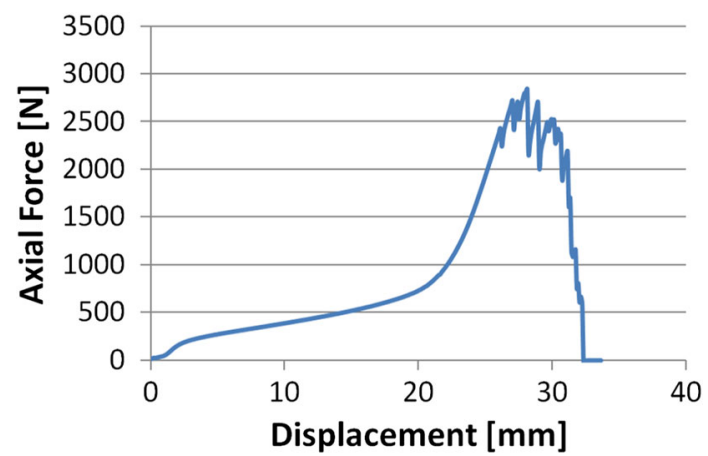

(b)

Fig. 30 Force versus displacement plots of BIAS extension test for a sample S2, b sample S3

A very similar overall behavior has been observed in BIAS extension tests of other inox-printed pantographic structures, as well as the failure mechanism (the extension of the external fibers is always involved), as shown in Fig. 31. In Fig. 30, the force versus displacement plots for the three inox samples are presented: The shapes of the curves are very similar. Likewise, the graphs point an acceleration in the work hardening mechanism around $20 \mathrm{~mm}$ of stretch that leads the specimens to exert the maximum reaction force at about $30 \mathrm{~mm}$ of stretch. A difference can be noted in the maximum value of the reaction of specimen S1, which is lower than other two, being about $2500 \mathrm{~N}$ the former and about $3000 \mathrm{~N}$ the latter. This response is likely due to the initial cyclic loading done on S1 specimen. However, strong similarities emerge from Figs. 30 and 31.

Another peculiarity behavior provided by the microstructure emerges from a BIAS extension test performed on inox sample S4, whose force versus displacement plot is shown in Fig. 32. Looking at the graph, it is noticeable that at about $8 \mathrm{~mm}$ of stretch the graph has a little dip that it could be related to a structural imperfection. However, this fact does not alter the overall behavior of the specimen that continues its strain hardening in the same way as the other inox samples. This last evidence proves that the pantographic structure is reliable also against constructive defects.

\section{Interpretation of experimental results: proposed models}

The experimental data described in the previous sections show that two types of rupture mechanisms can occur in the extension test of pantographic structures. Specifically, for the aluminum specimens, the failure, caused by the breaking of pivots, triggers at external point of their longer side. On the other hand, for the inox specimens, the onset of the rupture mechanism is located close to the vertices of the clamped edges. The different behavior can be related to the geometric features of the pivots, which are the most deformed element of the pantographic lattice. When the pivots have a slender shape, as in the case for the presented aluminum specimens, they undergo flexural deformation superimposed on to the twist deformation due to the relative rotation of the beams. Most of the experimental and numerical evidences in the literature consider pantographic structures characterized by short pivots with negligible flexibility. A numerical modeling of the 


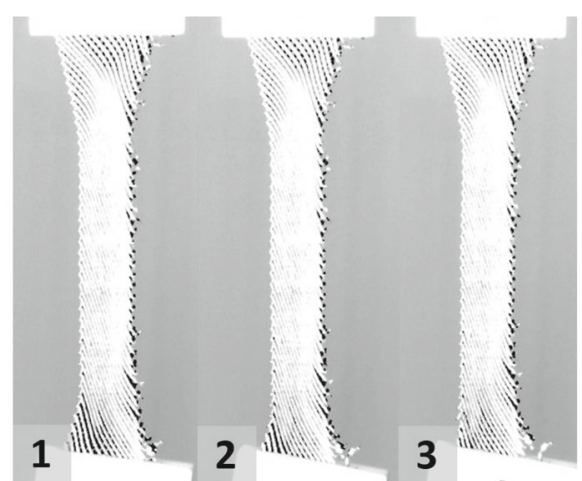

(a)

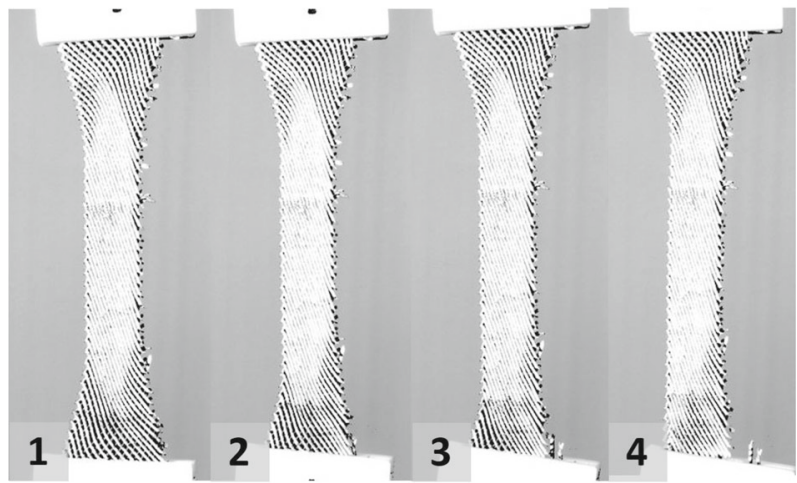

(b)

Fig. 31 Failure propagation under BIAS extension test for a sample S2, b sample S3

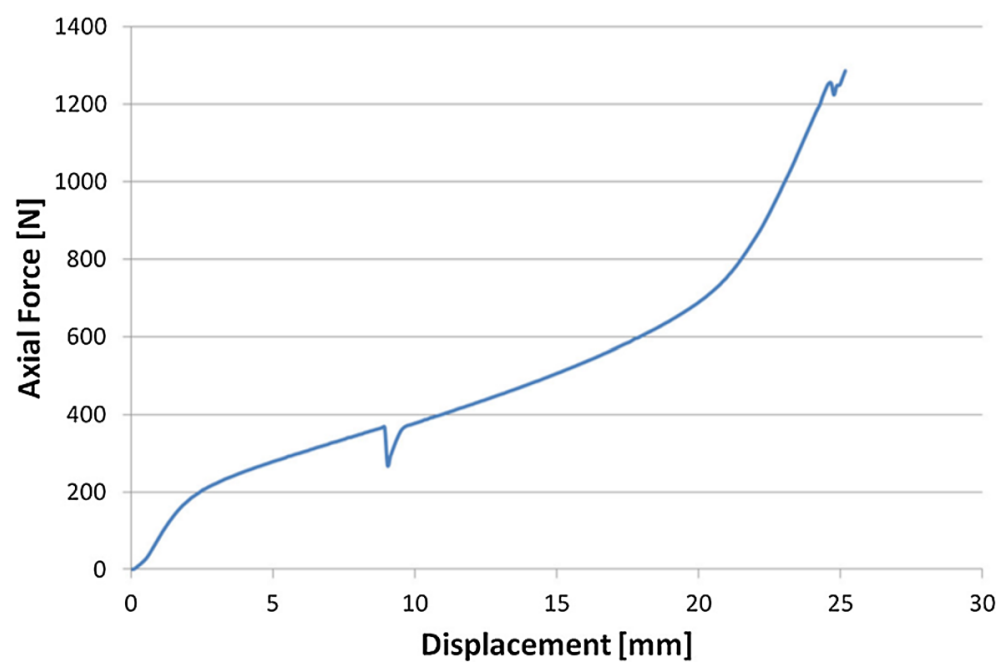

Fig. 32 Force versus displacement graph related to inox sample S4: the constructive defect indicated by the local dip at about 8 $\mathrm{mm}$ of extension does not influence the overall behavior of the specimen under BIAS extension test 


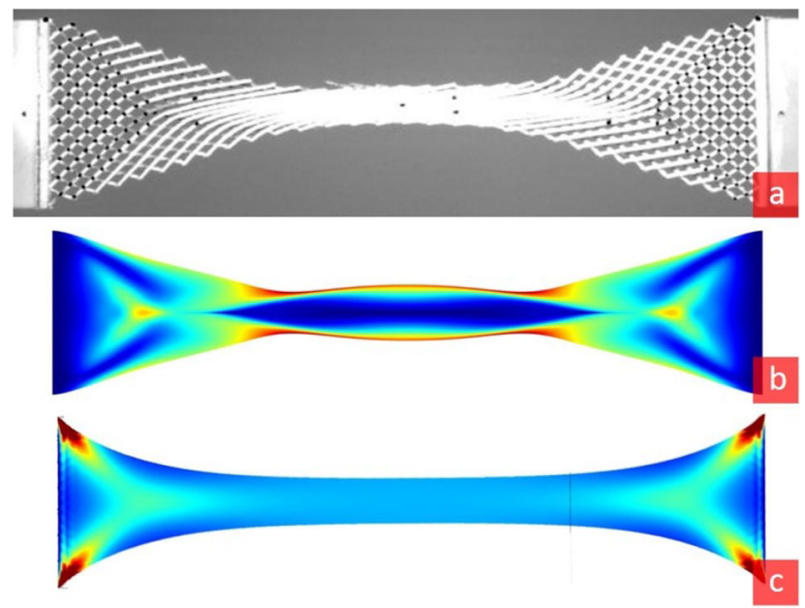

Fig. 33 Comparison between the deformation of an aluminum sample (a) and numerical simulations of a BIAS extension test for $\mathbf{b}$ two-placement field strain energy density of Eq. 2 and $\mathbf{c}$ one-placement field strain energy density of Eq. 1. Colors indicate strain energy density (color figure online)

mechanical behavior of such pantographic structures is possible using the homogenized expression of strain energy density for an elastic surface with a pantographic microstructure defined in [13], which is

$$
\begin{aligned}
W(\chi)= & \int_{\Omega} \sum_{\alpha} \frac{K_{e}^{\alpha}}{2}\left(\left\|\mathbf{F} \mathbf{D}_{\alpha}\right\|-1\right)^{2} \mathrm{~d} \Omega \\
& +\int_{\Omega} \sum_{\alpha} \frac{K_{b}^{\alpha}}{2}\left[\frac{\nabla \mathbf{F}\left|\mathbf{D}_{\alpha} \otimes \mathbf{D}_{\alpha} \cdot \nabla \mathbf{F}\right| \mathbf{D}_{\alpha} \otimes \mathbf{D}_{\alpha}}{\left\|\mathbf{F} \mathbf{D}_{\alpha}\right\|^{2}}-\left(\frac{\mathbf{F} \mathbf{D}_{\alpha}}{\left\|\mathbf{F} \mathbf{D}_{\alpha}\right\|} \cdot \frac{\nabla \mathbf{F}\left|\mathbf{D}_{\alpha} \otimes \mathbf{D}_{\alpha}\right|}{\left\|\mathbf{F} \mathbf{D}_{\alpha}\right\|}\right)^{2}\right] \mathrm{d} \Omega \\
& +\int_{\Omega} \frac{K_{p} \mid}{2}\left|\arccos \left(\frac{\mathbf{F D}_{1}}{\left\|\mathbf{F D}_{1}\right\|} \cdot \frac{\mathbf{F D}_{2}}{\left\|\mathbf{F} \mathbf{D}_{2}\right\|}\right)-\frac{\pi}{2}\right|^{\gamma} \mathrm{d} \Omega
\end{aligned}
$$

The expression in Eq. 1 depends upon a single placement field $\chi$, being $\mathbf{F}=\nabla \chi$, which does not consider the sliding between the two families of beams. Further investigations were the motivation for a series of papers $[17,22,32,64,64]$ concerning numerical simulations of BIAS extension tests performed by employing Eq. 1 as strain energy density. These works demonstrate that the homogenized model is able to describe the behavior of polyamide pantographic structures (i.e., the homogenized model predicts that the concentration of strain energy is located where the samples break, as shown by the plot in Fig. 33a). For different geometries of the microstructural elements, such as the case of the aluminum specimen, the flexibility of the pivots is no more negligible, and the strain energy density must also consider that the no sliding constrain between the two arrays of fibers does not hold. In [63], in order to describe the kinematics of the pantographic structure with slender pivots a modified version of the bi-dimensional elastic surface model has been presented, which, in contrast to [13], takes into account relative displacements between the two families of fibers. This assumption results in a homogenized form of strain energy which depends on two different placement fields and it is defined by

$$
\begin{aligned}
W\left(\chi^{\alpha}\right)= & \int_{\Omega} \frac{K_{e}^{\alpha}}{2}\left(\left\|\mathbf{F}^{\alpha} \mathbf{D}_{\alpha}\right\|-1\right)^{2} \mathrm{~d} \Omega \\
& +\int_{\Omega} \frac{K_{b}^{\alpha}}{2}\left[\frac{\nabla \mathbf{F}^{\alpha}\left|\mathbf{D}_{\alpha} \otimes \mathbf{D}_{\alpha} \cdot \nabla \mathbf{F}^{\alpha}\right| \mathbf{D}_{\alpha} \otimes \mathbf{D}_{\alpha}}{\left\|\mathbf{F}^{\alpha} \mathbf{D}_{\alpha}\right\|^{2}}-\left(\frac{\mathbf{F}^{\alpha} \mathbf{D}_{\alpha}}{\left\|\mathbf{F}^{\alpha} \mathbf{D}_{\alpha}\right\|} \cdot \frac{\nabla \mathbf{F}^{\alpha}\left|\mathbf{D}_{\alpha} \otimes \mathbf{D}_{\alpha}\right|}{\left\|\mathbf{F}^{\alpha} \mathbf{D}_{\alpha}\right\|}\right)^{2}\right] \mathrm{d} \Omega \\
& +\int_{\Omega} \frac{K_{p}}{2} \arccos \left(\frac{\mathbf{F}^{1} \mathbf{D}_{1}}{\left\|\mathbf{F}^{1} \mathbf{D}_{1}\right\|} \cdot \frac{\mathbf{F}^{2} \mathbf{D}_{2}}{\left\|\mathbf{F}^{2} \mathbf{D}_{2}\right\|}\right)-\frac{\pi}{2}^{\gamma} \mathrm{d} \Omega \\
& +\int_{\Omega} \frac{K_{\mathrm{int}}}{2}\left\|\chi^{1}-\chi^{2}\right\|^{2} \mathrm{~d} \Omega
\end{aligned}
$$

where the superscript $\alpha$ indicates the considered family of fibers. In Eq. 2, we used $\mathbf{F}^{\alpha}=\nabla \chi^{\alpha}$ and no sum over repeated $\alpha$ is intended. We refer to [63] for the comparison between the constants in Eqs. 1 and 2. This 
expression for the strain energy density describes the behavior of the pantographic system by means of two independent placements for each of the two fiber arrays, whose interaction is governed by the last term of Eq. 2, that is,

$$
\int_{\Omega} \frac{K_{\text {int }}}{2}\left\|\chi^{1}-\chi^{2}\right\|^{2} \mathrm{~d} \Omega
$$

By introducing the interaction term in Eq. 3, the rupture mechanism of pantographic structures can be numerically reproduced to provide a good match with experimental measurements. Indeed, in [63] it is shown that by employing Eq. 2 in a numerical simulation of extension test, higher values of strain energy density are found to be located precisely at external points on the longest sides. Clearly, the interaction term is necessary when the restrictive assumption in [13] does not hold. A qualitative comparison between strain energy density plots referring to one-placement field model and two-placement field model is shown in Fig. 33. It is noteworthy that Eq. 3 is characterized by the modulus $K_{\text {int }}$ which has to be related to the deformation of the pivots. As reported in [63], for high values of $K_{\text {int }}$, which is the case of very stiff pivots, the model produces the same results as that of the one-placement model found in [13]. Furthermore, the dependence of the stiffness $K_{\text {int }}$ upon the modulus of the relative displacement of the fibers can be employed to describe the deterioration of the mechanical properties of the specimen, i.e., for the definition of stepwise function in which $K_{\text {int }}$ changes depending on $\delta=\left|\chi^{1}-\chi^{2}\right|$. With the aim of forecasting the behavior of pantographic lattices and of defining their failure criteria, it can be remarked that to use a modified version of the strain energy density allows us to evaluate more cases as the one-field model results to be the limit of the two-field model for high values of $K_{\text {int }}$.

Further, we must remark that some similarities in behavior emerge when we compare results from polyamide specimens with the inox specimens. The pantographic microstructure of polyamide samples, as the inox ones, is designed with short pivots and, despite the great difference existing between the mechanical properties of the constituent material (i.e., the Young's modulus) which result, obviously, in much more stiffer specimens in terms of reaction force exerted, the rupture mechanism triggers near the clamped edges in both cases.

\section{Conclusion}

The experimental data regarding pantographic structure have been extended to new constitutive materials. The most innovative and promising manufacturing techniques have been used to print aluminum and inox-steel specimens, whose qualitative behavior (focusing on the determination of the elastic limit and plastic and failure process) under BIAS extension test has been tested. The acquired data about this novel metal-printed specimens are added to those already available regarding polyamide specimens. Comparisons can be made between the sets of pantographic structures shown in this work. Both the samples demonstrate the great compliance of the material which can reach large deformations. This feature is shared with the polyamide specimens tested in previous works, so it is possible to relate it to the specific pantographic microstructure rather then the constitutive material. Furthermore, the specimens tested exhibit reliability toward the failure process which never happens suddenly, but once triggered it gradually spreads. Clearly, the different material affects some of quantitative properties: As fundamental example, consider the range of the measured reaction force, influenced by the different Young's modulus. Furthermore, one has to notice that the inox-steel specimens have a capacity of greater deformation rather the aluminum samples if we consider that the long side of the inox specimens is less than half long as the aluminum ones. A main difference between the rupture nature of the two sets of specimens emerges. While in the case of aluminum specimen the resistance of the pivots is involved, in the inox case the failure must be related to the tensile strength of the fibers. Also, the region where the rupture triggers is different. Two models in the literature have been recalled with the aim of relating the type of failure to the mathematical model suitable to predict it. Strain gradient modeling has proved to be useful also in regularizing mesh-dependent problems in continuum damage and fracture mechanics, where localization of deformations is frequently observed. Implementation of such regularization in second gradient materials would be straightforward, also in view of parameters identification carried out in [65-69]. By means of a variational asymptotic procedure, in [70] it has been derived a one-dimensional continuum model for the description of finite motions of elastic planar slender pantographic structures, whose highly exotic features are discussed. We show that, remarkably, the deformation energy density of such continuum depends, like the Elastica, not only on the Lagrangian curvature but also on the elongation gradient. Such one-dimensional continuum exhibits phase transition and negative stiffness as well. 
Apart from the models considered here, an independent and novel approach to understand the large deformation of beams and networks of beams as pantographic structures to be investigated in the future is to regard a beam as the boundary curve of a two-dimensional manifold in a three-dimensional space. For this purpose, the curve is to be endowed with its own energy similar to the one not only in the context of lower-dimensional energetics [71] but also in a geometrically nonlinear framework [72] and in accordance with higher gradient elasticity accounting for boundary energetics elaborated in [73]. The advantage of this approach, particularly from a computational viewpoint, is that the bulk material acts to regularize the behavior of the beam allowing in this way to analyze the instabilities associated with thin beams, which seem to be very similar to the instabilities of thin films on an elastic foundation [74]. One could be interested in studying the behavior of pantographic structures when embedded in softer matrices. Indeed, for potential applications it could be necessary to consider multiphase pantographic metamaterials. For this aim, it would be interesting to refer to $[75,76]$ for the calculation of the effective properties of a planar alignment and of a bundle of fibers in a softer matrix. For some more general results, one can refer to [77-79].

Acknowledgements Mario Spagnuolo has received funding from the European Union's Horizon 2020 research and innovation program under the Marie Skłodowska Curie Grant Agreement No. 665850.

\section{References}

1. Barchiesi, E., Spagnuolo, M., Placidi, L.: Mechanical metamaterials: a state of the art. Math. Mech. Solids 24(1), 212-234 (2018)

2. Del Vescovo, D., Giorgio, I.: Dynamic problems for metamaterials: review of existing models and ideas for further research. Int. J. Eng. Sci. 80, 153-172 (2014)

3. di Cosmo, F., Laudato, M., Spagnuolo, M.: Acoustic metamaterials based on local resonances: homogenization, optimization and applications. In: Altenbach, H., et al. (eds.) Generalized Models and Non-classical Approaches in Complex Materials 1, pp. 247-274. Springer, Berlin (2018)

4. Laudato, M., Di Cosmo, F.: Euromech 579 arpino 3-8 April 2017: generalized and microstructured continua: new ideas in modeling and/or applications to structures with (nearly) inextensible fibers - a review of presentations and discussions. Contin. Mech. Thermodyn. 30(5), 1011-1025 (2018)

5. Alibert, J.-J., Seppecher, P., dell'Isola, F.: Truss modular beams with deformation energy depending on higher displacement gradients. Math. Mech. Solids 8(1), 51-73 (2003)

6. Seppecher, P., Alibert, J.-J., dell'Isola, F.: Linear elastic trusses leading to continua with exotic mechanical interactions. J. Phys. Conf. Ser. 319(1), 012018 (2011)

7. Alibert, J., Della Corte, A.: Second-gradient continua as homogenized limit of pantographic microstructured plates: a rigorous proof. Z. Angew. Math. Phys. 66(5), 2855-2870 (2015)

8. Barchiesi, E., Placidi, L.: A review on models for the 3D statics and 2D dynamics of pantographic fabrics. In: Sumbatyan, M.A. (ed.) Wave Dynamics and Composite Mechanics for Microstructured Materials and Metamaterials, pp. $239-258$. Springer, Berlin (2017)

9. Placidi, L., Andreaus, U., Giorgio, I.: Identification of two-dimensional pantographic structure via a linear d4 orthotropic second gradient elastic model. J. Eng. Math. 103(1), 1-21 (2017)

10. Placidi, L., Barchiesi, E., Turco, E., Rizzi, N.L.: A review on 2D models for the description of pantographic fabrics. Z. Angew. Math. Phys. 67(5), 121 (2016)

11. Khakalo, S., Balobanov, V., Niiranen, J.: Modelling size-dependent bending, buckling and vibrations of 2D triangular lattices by strain gradient elasticity models: applications to sandwich beams and auxetics. Int. J. Eng. Sci. 127, 33-52 (2018)

12. Khakalo, S., Niiranen, J.: Form II of Mindlin's second strain gradient theory of elasticity with a simplification: for materials and structures from nano-to macro-scales. Eur. J. Mech. A/Solids 71, 292-319 (2018)

13. dell'Isola, F., Giorgio, I., Pawlikowski, M., Rizzi, N.: Large deformations of planar extensible beams and pantographic lattices: heuristic homogenization, experimental and numerical examples of equilibrium. Proc. R. Soc. A 472(2185), 20150790 (2016)

14. dell'Isola, F., Seppecher, P., Alibert, J.J., Lekszycki, T., Grygoruk, R., Pawlikowski, M., Steigmann, D., Giorgio, I., Andreaus, U., Turco, E., et al.: Pantographic metamaterials: an example of mathematically driven design and of its technological challenges. Contin. Mech. Thermodyn. (2018). https://doi.org/10.1007/s00161-018-0689-8

15. Steigmann, D., dell'Isola, F.: Mechanical response of fabric sheets to three-dimensional bending, twisting, and stretching. Acta Mech. Sin. 31(3), 373-382 (2015)

16. Turco, E., dell'Isola, F., Cazzani, A., Rizzi, N.: Hencky-type discrete model for pantographic structures: numerical comparison with second gradient continuum models. Z. Angew. Math. Phys. 67, 85 (2016)

17. dell'Isola, F., Lekszycki, T., Pawlikowski, M., Grygoruk, R., Greco, L.: Designing a light fabric metamaterial being highly macroscopically tough under directional extension: first experimental evidence. Z. Angew. Math. Phys. 66, 3473-3498 (2015)

18. Turco, E., Giorgio, I., Misra, A., dell'Isola, F.: King post truss as a motif for internal structure of (meta) material with controlled elastic properties. R. Soc. Open Sci. 4(10), 171153 (2017)

19. Giorgio, I., Rizzi, N., Turco, E.: Continuum modelling of pantographic sheets for out-of-plane bifurcation and vibrational analysis. Proc. R. Soc. A 473(2207), 20170636 (2017)

20. Challamel, N., Kocsis, A., Wang, C.: Discrete and non-local elastica. Int. J. Non-Linear Mech. 77, 128-140 (2015)

21. Turco, E., Misra, A., Pawlikowski, M., dell'Isola, F., Hild, F.: Enhanced Piola-Hencky discrete models for pantographic sheets with pivots without deformation energy: numerics and experiments. Int. J. Solids Struct. 147, 94-109 (2018) 
22. Giorgio, I.: Numerical identification procedure between a micro-Cauchy model and a macro-second gradient model for planar pantographic structures. Z. Angew. Math. Phys. 67(4), 95 (2016)

23. dell'Isola, F., Della Corte, A., Greco, L., Luongo, A.: Plane bias extension test for a continuum with two inextensible families of fibers: a variational treatment with Lagrange multipliers and a perturbation solution. Int. J. Solids Struct. 81, 1-12 (2015)

24. Battista, A., Cardillo, C., Del Vescovo, D., Rizzi, N., Turco, E.: Frequency shifts induced by large deformations in planar pantographic continua. Nanomech. Sci. Technol. Int. J. 6(2), 161-178 (2015)

25. Altenbach, H., Eremeyev, V.: On the linear theory of micropolar plates. ZAMM J. Appl. Math. Mech. 89(4), 242-256 (2009)

26. Pietraszkiewicz, W., Eremeyev, V.: On natural strain measures of the non-linear micropolar continuum. Int. J. Solids Struct. 46(3), 774-787 (2009)

27. Eremeyev, V.A., Pietraszkiewicz, W.: Material symmetry group and constitutive equations of micropolar anisotropic elastic solids. Math. Mech. Solids 21(2), 210-221 (2016)

28. Eremeyev, V.A., Pietraszkiewicz, W.: Local symmetry group in the general theory of elastic shells. J. Elast. 85(2), 125-152 (2006)

29. Eremeyev, V.A.: On the material symmetry group for micromorphic media with applications to granular materials. Mech. Res. Commun. 94, 8-12 (2018)

30. Boutin, C., Giorgio, I., Placidi, L., et al.: Linear pantographic sheets: asymptotic micro-macro models identification. Math. Mech. Complex Syst. 5(2), 127-162 (2017)

31. Eremeyev, V.A., dell'Isola, F., Boutin, C., Steigmann, D.: Linear pantographic sheets: existence and uniqueness of weak solutions. J. Elast. 132, 175-196 (2017)

32. Rahali, Y., Giorgio, I., Ganghoffer, J., dell'Isola, F.: Homogenization à la Piola produces second gradient continuum models for linear pantographic lattices. Int. J. Eng. Sci. 97, 148-172 (2015)

33. Andreaus, U., Spagnuolo, M., Lekszycki, T., Eugster, S.R.: A Ritz approach for the static analysis of planar pantographic structures modeled with nonlinear Euler-Bernoulli beams. Contin. Mech. Thermodyn. 30, 1103-1123 (2018)

34. dell'Isola, F., Della Corte, A., Giorgio, I., Scerrato, D.: Pantographic 2D sheets: discussion of some numerical investigations and potential applications. Int. J. Non-Linear Mech. 80, 200-208 (2016)

35. Berezovski, A., Giorgio, I., Corte, A.D.: Interfaces in micromorphic materials: wave transmission and reflection with numerical simulations. Math. Mech. Solids 21(1), 37-51 (2016)

36. Abali, B., Müller, W., dell'Isola, F.: Theory and computation of higher gradient elasticity theories based on action principles. Arch. Appl. Mech. 87(9), 1495-1510 (2017)

37. Camar-Eddine, M., Seppecher, P.: Closure of the set of diffusion functionals with respect to the Mosco-convergence. Math. Models Methods Appl. Sci. 12(08), 1153-1176 (2002)

38. Camar-Eddine, M., Seppecher, P.: Determination of the closure of the set of elasticity functionals. Arch. Ration. Mech. Anal. 170(3), 211-245 (2003)

39. Camar-Eddine, M., Seppecher, P.: Non-local interactions resulting from the homogenization of a linear diffusive medium. C. R. l'Acad. Sci. Ser. I Math. 332(5), 485-490 (2001)

40. Carcaterra, A., dell'Isola, F., Esposito, R., Pulvirenti, M.: Macroscopic description of microscopically strongly inhomogeneous systems: a mathematical basis for the synthesis of higher gradients metamaterials. Arch. Ration. Mech. Anal. 218(3), 1239-1262 (2015)

41. Challamel, N., Kocsis, A., Wang, C.: Higher-order gradient elasticity models applied to geometrically nonlinear discrete systems. Theor. Appl. Mech. 42(4), 223-248 (2015)

42. Esposito, R., Pulvirenti, M.: From particles to fluids. Handb. Math. Fluid Dyn. 3, 1-82 (2004)

43. Pulvirenti, M.: Kinetic limits for stochastic particle systems. In: Probabilistic Models for Nonlinear Partial Differential Equations, pp. 96-126. Springer, Berlin (1996)

44. Sánchez-Palencia, E.: Non-homogeneous media and vibration theory, Lecture notes in physics, vol. 127 (1980)

45. Bensoussan, A., Lions, J.-L., Papanicolaou, G.: Asymptotic Analysis for Periodic Structures, vol. 5. North-Holland Publishing Company, Amsterdam (1978)

46. Carinci, G., De Masi, A., Giardinà, C., Presutti, E.: Super-hydrodynamic limit in interacting particle systems. J. Stat. Phys. 155(5), 867-887 (2014)

47. Carinci, G., De Masi, A., Giardinà, C., Presutti, E.: Hydrodynamic limit in a particle system with topological interactions. Arab. J. Math. 3(4), 381-417 (2014)

48. De Masi, A., Merola, I., Presutti, E., Vignaud, Y.: Coexistence of ordered and disordered phases in Potts models in the continuum. J. Stat. Phys. 134(2), 243-306 (2009)

49. De Masi, A., Olla, S.: Quasi-static hydrodynamic limits. J. Stat. Phys. 161(5), 1037-1058 (2015)

50. De Masi, A., Luckhaus, S., Presutti, E.: Two scales hydrodynamic limit for a model of malignant tumor cells. Ann. l'Inst. Henri Poincare (B) Prob. Stat. 43(3), 257-297 (2007)

51. De Masi, A., Galves, A., Löcherbach, E., Presutti, E.: Hydrodynamic limit for interacting neurons. J. Stat. Phys. 158(4), 866-902 (2015)

52. Jia, H., Misra, A., Poorsolhjouy, P., Liu, C.: Optimal structural topology of materials with micro-scale tension-compression asymmetry simulated using granular micromechanics. Mater. Des. 115, 422-432 (2017)

53. Misra, A., Poorsolhjouy, P.: Grain-and macro-scale kinematics for granular micromechanics based small deformation micromorphic continuum model. Mech. Res. Commun. 81, 1-6 (2017)

54. Misra, A., Poorsolhjouy, P.: Granular micromechanics model for damage and plasticity of cementitious materials based upon thermomechanics. Math. Mech. Solids (2015). https://doi.org/10.1177/1081286515576821

55. Ravari, M.K., Kadkhodaei, M., Badrossamay, M., Rezaei, R.: Numerical investigation on mechanical properties of cellular lattice structures fabricated by fused deposition modeling. Int. J. Mech. Sci. 88, 154-161 (2014)

56. Ravari, M.K., Esfahani, S.N., Andani, M.T., Kadkhodaei, M., Ghaei, A., Karaca, H., Elahinia, M.: On the effects of geometry, defects, and material asymmetry on the mechanical response of shape memory alloy cellular lattice structures. Smart Mater. Struct. 25(2), 025008 (2016) 
57. Ravari, M.K., Kadkhodaei, M.: A computationally efficient modeling approach for predicting mechanical behavior of cellular lattice structures. J. Mater. Eng. Perform. 24(1), 245-252 (2015)

58. Ravari, M.K., Kadkhodaei, M., Ghaei, A.: A unit cell model for simulating the stress-strain response of porous shape memory alloys. J. Mater. Eng. Perform. 24(10), 4096-4105 (2015)

59. Rezaei, R., Karamooz Ravari, M., Badrossamay, M., Kadkhodaei, M.: Mechanical characterization and finite element modeling of polylactic acid BCC-Z cellular lattice structures fabricated by fused deposition modeling. Proc. Inst. Mech. Eng. Part C J. Mech. Eng. Sci. 231(11), 1995-2004 (2017)

60. Misra, A., Lekszycki, T., Giorgio, I., Ganzosch, G., Müller, W.H., dell'Isola, F.: Pantographic metamaterials show atypical Poynting effect reversal. Mech. Res. Commun. 89, 6-10 (2018)

61. Barchiesi, E., Ganzosch, G., Liebold, C., Placidi, L., Grygoruk, R., Müller, W.H.: Out-of-plane buckling of pantographic fabrics in displacement-controlled shear tests: experimental results and model validation. Contin. Mech. Thermodyn. 31(1), 33-45 (2018)

62. Zhang, D.: Entwicklung des selective laser melting (SLM) für Aluminiumwerkstoffe. Shaker, Aachen (2004)

63. Spagnuolo, M., Barcz, K., Pfaff, A., dell'Isola, F., Franciosi, P.: Qualitative pivot damage analysis in aluminum printed pantographic sheets: numerics and experiments. Mech. Res. Commun. 83, 47-52 (2017)

64. dell'Isola, F., Della Corte, A., Giorgio, I.: Higher-gradient continua: the legacy of Piola, Mindlin, Sedov and Toupin and some future research perspectives. Math. Mech. Solids 22(4), 852-872 (2016)

65. Placidi, L., Barchiesi, E., Battista, A.: An inverse method to get further analytical solutions for a class of metamaterials aimed to validate numerical integrations. In: Mathematical Modelling in Solid Mechanics, pp. 193-210. Springer, Berlin (2017)

66. Placidi, L., Barchiesi, E.: Energy approach to brittle fracture in strain-gradient modelling. Proc. R. Soc. A 474(2210), 20170878 (2018)

67. Placidi, L., Misra, A., Barchiesi, E.: Two-dimensional strain gradient damage modeling: a variational approach. Z. Angew. Math. Phys. 69(3), 56 (2018)

68. Placidi, L., Barchiesi, E., Misra, A.: A strain gradient variational approach to damage: a comparison with damage gradient models and numerical results. Math. Mech. Complex Syst. 6(2), 77-100 (2018)

69. Placidi, L., Misra, A., Barchiesi, E.: Simulation results for damage with evolving microstructure and growing strain gradient moduli. Contin. Mech. Thermodyn. (2018). https://doi.org/10.1007/s00161-018-0693-z

70. Barchiesi, E., dell'Isola, F., Laudato, M., Placidi, L., Seppecher, P.: A 1d continuum model for beams with pantographic microstructure: asymptotic micro-macro identification and numerical results. In: dell'Isola, F., Eremeyev, V.A., Porubov, A. (eds.) Advances in Mechanics of Microstructured Media and Structures, pp. 43-74. Springer, Berlin (2018)

71. Javili, A., McBride, A., Steinmann, P.: Thermomechanics of solids with lower-dimensional energetics: on the importance of surface, interface, and curve structures at the nanoscale. A unifying review. Appl. Mech. Rev. 65(1), 010802 (2013)

72. Javili, A., McBride, A., Steinmann, P., Reddy, B.: A unified computational framework for bulk and surface elasticity theory: a curvilinear-coordinate-based finite element methodology. Comput. Mech. 54(3), 745-762 (2014)

73. Javili, A., dell'Isola, F., Steinmann, P.: Geometrically nonlinear higher-gradient elasticity with energetic boundaries. J. Mech. Phys. Solids 61(12), 2381-2401 (2013)

74. Javili, A., Dortdivanlioglu, B., Kuhl, E., Linder, C.: Computational aspects of growth-induced instabilities through eigenvalue analysis. Comput. Mech. 56(3), 405-420 (2015)

75. Franciosi, P., Spagnuolo, M., Salman, O.U.: Mean green operators of deformable fiber networks embedded in a compliant matrix and property estimates. Contin. Mech. Thermodyn. 31, 101-132 (2018)

76. Franciosi, P.: A decomposition method for obtaining global mean green operators of inclusions patterns. Application to parallel infinite beams in at least transversally isotropic media. Int. J. Solids Struct. 147, 1-19 (2018)

77. Franciosi, P., Lormand, G.: Using the radon transform to solve inclusion problems in elasticity. Int. J. Solids Struct. 41(3-4), 585-606 (2004)

78. Franciosi, P., El Omri, A.: Effective properties of fiber and platelet systems and related phase arrangements in n-phase heterogenous media. Mech. Res. Commun. 38(1), 38-44 (2011)

79. Franciosi, P.: The boundary-due terms in the green operator of inclusion patterns from distant to contact and to connected situations using radon transforms: illustration for spheroid alignments in isotropic media. Int. J. Solids Struct. 47(2), 304-319 (2010) 